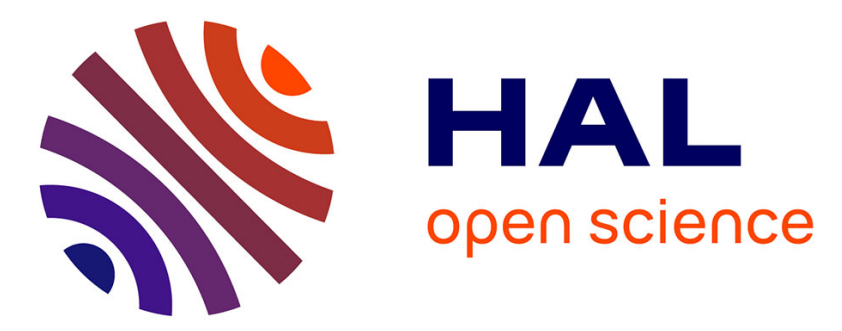

\title{
Mesoscale modelling of tensile response and damage evolution in natural fibre reinforced laminates
}

Zia Mahboob, Yves Chemisky, Fodil Meraghni, Habiba Bougherara

\section{To cite this version:}

Zia Mahboob, Yves Chemisky, Fodil Meraghni, Habiba Bougherara. Mesoscale modelling of tensile response and damage evolution in natural fibre reinforced laminates. Composites Part B: Engineering, 2017, 119, pp.168-183. 10.1016/j.compositesb.2017.03.018 . hal-02412996

\section{HAL Id: hal-02412996 https://hal.science/hal-02412996}

Submitted on 16 Dec 2019

HAL is a multi-disciplinary open access archive for the deposit and dissemination of scientific research documents, whether they are published or not. The documents may come from teaching and research institutions in France or abroad, or from public or private research centers.
L'archive ouverte pluridisciplinaire HAL, est destinée au dépôt et à la diffusion de documents scientifiques de niveau recherche, publiés ou non, émanant des établissements d'enseignement et de recherche français ou étrangers, des laboratoires publics ou privés. 


\title{
Mesoscale modelling of tensile response and damage evolution in natural fibre reinforced laminates
}

\author{
Zia Mahboob a, Yves Chemisky ${ }^{\text {b }}$, Fodil Meraghni ${ }^{\text {b }}$, Habiba Bougherara ${ }^{\text {a, * }}$ \\ ${ }^{a}$ Department of Mechanical \& Industrial Engineering, Ryerson University, Toronto, ON, Canada \\ ${ }^{\mathrm{b}}$ Arts et Métiers ParisTech Metz, LEM3 UMR CNRS 7239, Metz, France
}

\begin{abstract}
A B S T R A C T
A continuum damage mechanics based mesoscale model is developed within a thermodynamics framework to describe the in-plane tensile response in natural fibre composites. The standard Mesoscale Damage Theory (MDT) is modified to incorporate damage and inelasticity evolution in the fibredirection, thereby capturing the unique nonlinear fibre-direction response evidenced in natural fibre composites (NFC). The multi-ply damage model is validated using tests on Flax/epoxy laminates and available data on Carbon/epoxy laminates. Model parameters are identified for Flax/epoxy by applying an optimisation algorithm that compares numerical predictions with experimental data. Predictions of mechanical response, stiffness degradation, and inelasticity correlate very well with experimental observations of Flax-laminates. This modified-MDT model offers a predictive, robust tool to aid the development of NFC engineering structures.
\end{abstract}

\section{Introduction}

Natural, plant-based fibres have been shown to have considerable potential in replacing synthetic engineering fibres as reinforcement in composites [1-6]. Favourable mechanical, economic, and renewable characteristics have made natural fibre based composites (NFC) a popular class of material, as evidenced by a recent surge of publications on the subject [7-15]. Compared to synthetic-fibre composites, plant-based NFCs are low-cost and lightweight, require less energy to manufacture [3], are $\mathrm{CO}_{2}$-neutral [16], easier to tool and less toxic during processing [3,16], and result in simpler, non-toxic recycling $[1,10,16]$. They also offer good specific mechanical properties $[4,7,17,18]$, good thermal and acoustic insulation [7], and greater energy absorption at high strain rates [19]. In pursuit of developing sustainable, environment-friendly composites for load-bearing applications, Flax fibre (Linum usitatissimum L.) has been shown to compare most favourably with Glass fibre, when considering other plant fibres, e.g. hemp, sisal, jute, bamboo $[2,5,7,20]$. Flax fibre performance is reported to match or exceed Glass fibre in specific strength (1300 vs $1350 \mathrm{MPa} / \mathrm{g}$ $\mathrm{cm}^{-3}$ ) [2], specific modulus (20-70 vs $\left.30 \mathrm{GPa} / \mathrm{g}-\mathrm{cm}^{-3}\right)$ [2,7], cost per weight (0.5-1.5 vs $1.6-3.25 \mathrm{USD} / \mathrm{kg}$ ) [2], cost per length required to resist $100 \mathrm{kN}(0.05-0.65$ vs $0.1-0.4 \mathrm{USD} / \mathrm{m})$ [2], and production energy consumption (11.4 vs $50 \mathrm{MJ} / \mathrm{kg}$ ) [5]. Several obstacles to the mainstream industrial acceptance of NFCs have been identified that are subjects of ongoing research: flammability and lower resistance to ignition $[7,16,20]$, limited range of operating temperatures [7], hygrophilic unless waterproofed [21-25], fibrematrix bonding strength [17,23,26-29], nonlinear fibre response [16,21,30-32], limited mechanical data on composites [33,34], and a notable scarcity of validated models to accurately predict their internal damage. Successful innovation and adoption of highperformance NFCs depends on an accurate understanding of their physical damage mechanisms, supported by the development of predictive mechanical behaviour models that can emulate these mechanisms. Predicting damage initiation, damage progression, and development of failure conditions is essential to reliably design engineering components - and such capability remains relatively immature for NFCs when compared to traditional Carbon or Glass composites. Note that, in this study, natural fibres refer to plantbased fibres only. This study develops a damage mechanics based model of in-plane tensile response in NFCs that accounts for their unique nonlinear fibre-direction response and internal damage progression. Considering Flax fibres have been shown to be the most promising natural fibre candidate for engineering applications, the model developed in this study is based on tensile test 
observations of a Flax fibre reinforced composite, thereby identifying Flax-specific model parameters.

\subsection{Damage mechanisms in plant fibres and their composites}

Damage may be thought of as surface or volume discontinuities (microcracks and microvoids) [35,36]. Different types of damaging mechanisms encourage the development of such physical discontinuities, resulting in continuously evolving (typically degrading) material properties until the eventual failure of load-carrying capacity [36-38]. Flax fibres are known to exhibit a varying stiffness and inelastic deformation under tension [30]. 'Loop' tests on elementary (single) Flax fibres show that plastic deformation begins in the compressive side of the loop, whereas failure occurs on the tensile side. The primary cell walls break in a brittle manner, while the fibrillar secondary cell walls tend to split along the fibre length and also exhibit coarse crack progressions [39]. Romhány et al. [40] investigated tensile failure of Flax fibre bundles (or technical fibres) using acoustic emissions and in situ SEM inspection, and found the sequence of failure in a fibre bundle to be (i) axial splitting along the elementary fibre boundaries (breakdown of pectin layers), followed by (ii) radial or transverse cracking in elementary fibres, concluding with (iii) merging of the axial splits and transverse cracks leading to complete fracture of elementary fibres and microfibrils.

Tensile damage in composites of natural fibres share some similarity with well-known composite damage mechanisms. NFCs demonstrate a nonlinear response, with an initial rapid stiffness degradation rate that eventually decreases - unlike composites of synthetic fibres e.g. Glass where stiffness degradation tends to be constant and linear $[41,42]$. This difference in response is attributed to the inherent non-homogeneous nature of natural fibres: hierarchical structure [30,39,43], defects in individual fibres [44-46], and variable fibre geometry $[47,48]$. Depending on the matrix material used in the composite, some or all of the following distinct damage progression mechanisms have been identified through studies on NFC microstructure: (i) microfibril reorientation in the natural fibre secondary cell wall, (ii) 'intra-bundle' cracking, indicating splitting apart or separation of elementary fibres within a yarn bundle, (iii) transverse cracking in fibres, (iv) 'circum-bundle' interfacial cracks along the fibre-matrix boundary that indicate debonding or peeling, and (v) matrix shear cracks [23,49-59].

Under tensile loading, the combined progress of fibre transverse cracking and axial splitting leads to fibre breakage [40,50]. The circum-bundle propagation of fibre-matrix debonding is understood to be the precursor to fibre 'pull-out' evidenced on tensile fracture surfaces of NFC composites [49,52,59]. Interestingly, matrix cracks are not significantly reported [57-59] or considered critical to composite failure in Flax-reinforced composites. Under both tensile and compressive loading, similar fibre-matrix interfacial cracks of adjacent fibre bundles merge and propagate along inter-laminar boundaries (between plies) to cause eventual delamination before fracture $[51,59]$.

\subsection{Modelling mechanical properties and damage evolution in NFCS}

Well-known semi-empirical models and polynomial-based failure criteria (e.g. rule-of-mixtures, Halpin-Tsai equation, shear lag models, Maximum Stress criterion, Tsai-Hill criterion etc.) have been shown to reliably predict NFC tensile modulus and strength, as shown in the works of Facca et al. [60,61], Hughes et al. [41], and Shah et al. [53]. Andersons et al. [62] proposed a semi-empirical model whereby tensor-based orthotropic stress-strain relationships were made to fit experimental observations of single ply Flax- composites, and classical laminate theory was employed to simulate laminate tensile response. The authors showed that a purely macroscale analytical approach can offer reasonable reproductions of nonlinear behaviour in NFC UD-laminates - except for $[ \pm 45]_{\mathrm{nS}}$ layups, where the simulated response diverges from the experimental after $\sim 0.8-1.0 \%$ strain. This, the authors note, is because the 'rotation' of the angled plies (changing of ply orientation) in the test specimens is not accounted for in the model [62]. Recently, Panamoottil et al. [63] demonstrated a 'hierarchical' approach to simulate tensile response of a single resin-impregnated Flax yarn. Analytical microscale models (experimentally validated) are developed separately for elementary Flax fibre, matrix resin, and the fibre-matrix interphase layer, which are then combined in a finite element based 'unit model' of a Flax yarn (bundle of elementary fibres) impregnated and surrounded by matrix. A salient feature of this work is that the elementary fibres are treated as composites themselves, idealised as cylindrical tubes of varying diameters, reinforced by microfibrils at variable orientations, governed by classical laminate theory. Plastic yield and failure in all material phases are predicted by polynomial criteria. The authors intend to eventually simulate a full NFC laminate in the future by building a macromodel of repeated units of aforementioned micromodel [63].

NFCs are known to accumulate progressive damage and permanent deformation well before final failure [53,56,59]. Analytical models, such as those discussed above, can be calibrated to capture initial undamaged mechanical properties, overall laminate nonlinear response, and final failure in composites of different natural fibres at varying fibre volume fractions and ply orientations. However, these models do not typically offer the means to predict the initiation and evolution of internal damage or permanent strains - as can be done when taking a damage mechanics approach to modelling. Continuum Damage Mechanics (CDM) techniques apply continuum constitutive models wherein damage and inelasticity are quantified by evolving internal state variables and associated thermodynamic forces that represent, directly or indirectly, the distribution of microdefects in the material $[36,64]$. Panamoottil et al. [58]. proposed another semi-empirical approach to model UD Flax/polypropylene tensile response that does incorporate a progressive degradation of stiffness. The authors implement a tensorial anisotropic elasticity relationship where a damage effect tensor degrades the laminate compliance. This damage effect tensor is defined in terms of crack densities measured from direct microscropic observation of physical cracking in tested specimens (microstructure imaged at the three orthotropic planes), following the work of Voyiadjis and Venson [65]. Note that only cracks within and around Flax bundles were measured, since matrix cracks were not detected. Measurements were taken from specimens tested at various load levels up to failure, in order to quantify damage tensor entries for those load levels. When executed, the model produces a poor reproduction of experimental monotonic response for single plies, however, the simulation improves for a five-ply UD laminate [58]. No simulation results are reported for transverse or shear response. While this approach offers a direct means to estimate progressive stiffness degradation damage in terms of physical crack density, it is perhaps better suited for UD plies, not multiorientation laminates where crack identification and measurement will prove a cumbersome exercise. Furthermore, this approach is not developed within a framework of thermodynamics, so it is unable to follow inelasticity evolution and predict permanent strains.

Poilâne et al. [66] developed a thermodynamics and CDM-based viscoelastoplastic model for fibre-direction-only tensile response in a single-ply Flax/epoxy composite. The strain response was 
considered split into pure elastic, viscoelastic, and viscoplastic components. Based on observations from creep and repeated loadunload tests, the authors propose free energy and dissipation potentials that capture plastic yielding, temperature dependence and strain rate effects in the fibre-direction. Notably, the proposed model (i) does not incorporate or define any damage state variable (i.e. no degradation of mechanical properties is allowed for), and (ii) viscoplastic behaviour is modelled as a combination of classical linear kinematic hardening (pure translation of fibre-direction elastic domain) and a nonlinear kinematic hardening (translation coupled with contraction of elastic domain). As such, while material modulus is assumed constant, the irreversible effects of damaging phenomena was considered captured in the plasticity laws. Note that this assumption of constant fibre-direction stiffness is an approximation of Flax/epoxy response, which has been shown to have a clear stiffness degradation at room temperature by Mahboob et al. [59]. The authors Poilâne et al. concluded that fibredirection (i) viscous deformation exists at any temperature, (ii) viscoelastic effects are not significant at room temperature, so (iii) Flax/epoxy nonlinear behaviour can be attributed to plastic (or viscoplastic) effects, (iv) that are well captured by a combined linear and nonlinear kinematic hardening model [66].

Recently, Sliseris et al. [67] proposed two CDM-based micromechanical models within a thermodynamic framework: one for a random distribution short-fibre Flax/polypropylene, and another for a single-ply woven fabric Flax/epoxy composite, both under tension. For the short-fibre Flax/polypropylene model, fibre length and diameter were randomly distributed, and separate constitutive laws were defined for (i) elementary Flax fibre, (ii) 'defected' regions of elementary fibre, (iii) regions between elementary fibres but within overall yarn bundle (intra-bundle), and (iv) matrix resin. An interesting feature is that the authors chose to separately distinguish material behaviour in fibre defect regions and in intrabundle regions to better reflect reported observations of kinkbands and of weak pectin-hemicellulose adhesion between elementary Flax fibres in a bundle, respectively. The fibres were modelled simply as linear elastic (constant stiffness), but the defected fibre and intra-bundle regions were modelled as brittle materials with linearly degrading stiffness (damage variable defined) after a specified threshold. The matrix is modelled with constant stiffness and von Mises plasticity with isotropic hardening. For the woven fabric Flax/epoxy model, both Flax fibre and matrix were governed by nonlinear, isotropic hardening plasticity laws, but with no state variable laws that would permit any degradation of material properties. Both models were exercised via a finite element based RVE (representative volume element) loaded in tension. The models captured the initiation and progressive evolution of 'damaged zones' (locations that develop plasticity or fibre damage), and the RVE response closely reproduced experimentally observed nonlinear stress-strain response [67].

Since thermodynamics based CDM techniques are able to (i) make predictions of damage initiation within plies from an undamaged state (unlike fracture mechanics methods that require a pre-existing crack) and (ii) capture the evolution of interim diffuse damage within each ply until rupture (unlike the failure-criteriabased analytical approaches that can only track ply failures), the present study models damaged mechanical response in Flaxlaminates by modifying an existing mesoscale CDM framework developed at LMT-Cachan (Laboratoire de Mécanique et Technologie, Cachan, France), described by Ladevèze and others $[35,68,69]$. Named the Mesoscale Damage Theory (MDT) by Herakovich [35], it is the basis for a large number of CDM models in literature, and has been shown to be robust in predicting damaged response of composite structures under a variety of conditions
[35,70-84]. 'Meso'-scale implies that the scale of analysis is between that of micromechanics (the level of constituents) and laminate analysis (macroscale). The main assumption in this framework is that laminate response under any loading until fracture can be predicted by modelling two elementary mesoscale entities: the ply and the interface, and a constitutive law is developed for each that includes inelasticity and damage. Typically, the interface layer is idealised as a mechanical surface that connects two plies, and only included in the model when delamination or out-of-plane deformation is of interest [71,72,74]. Applying the concept of mean effective stress, the hypothesis of strain equivalence, and based on the thermodynamics of irreversible processes [37,38], the standard MDT model predicts in-plane damage growth in a single ply due to damage mechanisms that change material properties in the fibre-direction, transverse direction, and in-plane shear - each represented by a unique damage variable $[68,69]$. The model, as adapted in this study, will be further described in the following sections.

While the approach of Andersons et al. [62] offers a convenient macroscale method to simulate overall stress-strain response of multi-orientation Flax-laminates, capturing internal damage and residual inelasticity is out of its scope. The microscale models proposed by Sliseris et al. [67], while demonstrating that individual damaging mechanisms may be modelled separately, (i) assumes fibre modulus degradation only in the kink-bands and intra-bundle regions (ignores other fibre damage effects, e.g. cell wall reorganisation or cracking), which are (ii) modelled as brittle, simple linear function degradations (may not reflect reported nonlinear, continuous damage evolution [56,59]), and (iii) are not validated for UD off-axis loading. Poilâne et al. [66] showed a well-validated means of incorporating rate effects (viscoelasticity and viscoplasticity) at the mesoscale ply-level, but assumes the nonlinear response to be completely due to viscous or plastic deformation, and therefore does not allow for material damage effects in their model formulation. Considering that Flax/epoxy fibre-direction modulus reduces by $\sim 20 \%$ at room temperature [59], ignoring this loss of stiffness (or any other degradation effect of damage) is an inaccurate assumption that unduly magnifies the role of plastic effects. While the assumption may yet allow a reasonable simulation of fibre-direction response, the model needs further expansion by incorporating damage kinematics in order to capture tensile response in transverse and shear planes, or even compressive response - all of which exhibit up to 50\% stiffness degradation [59].

As such, in this study we submit a mesoscale alternative to recently proposed models that quantifies and couples material damage and inelasticity, proposing nonlinear evolutions for both based on experimental observations, thereby allowing a ply-level scrutiny of initiation and progression along the principal orthotropic directions of a multi-directionally reinforced NFC laminate with Flax/epoxy-specific model parameters identified.

\section{Experiments}

\subsection{Manufacturing}

A review of typical factors affecting manufacturing of NFCs can be found in Refs. $[13,85]$. In this study, commercially available dry UD FlaxPly $^{\circledR}$ (Lineo NV, Belgium [86]) with areal density $150 \mathrm{~g} / \mathrm{m}^{2}$ was used as reinforcement. Laboratory measurements indicate the Flax fabric has a density of $1.47 \pm 0.24 \mathrm{~g} / \mathrm{cm}^{3}$. A total of sixteen layers were used to manufacture every composite laminate tested in this study. The fabric architecture is predominantly unidirectional held together by a periodic cross-weave, with 40 strands in the $0^{\circ}$-direction and 3 across within a unit-squared area (Fig. 1). Each strand 


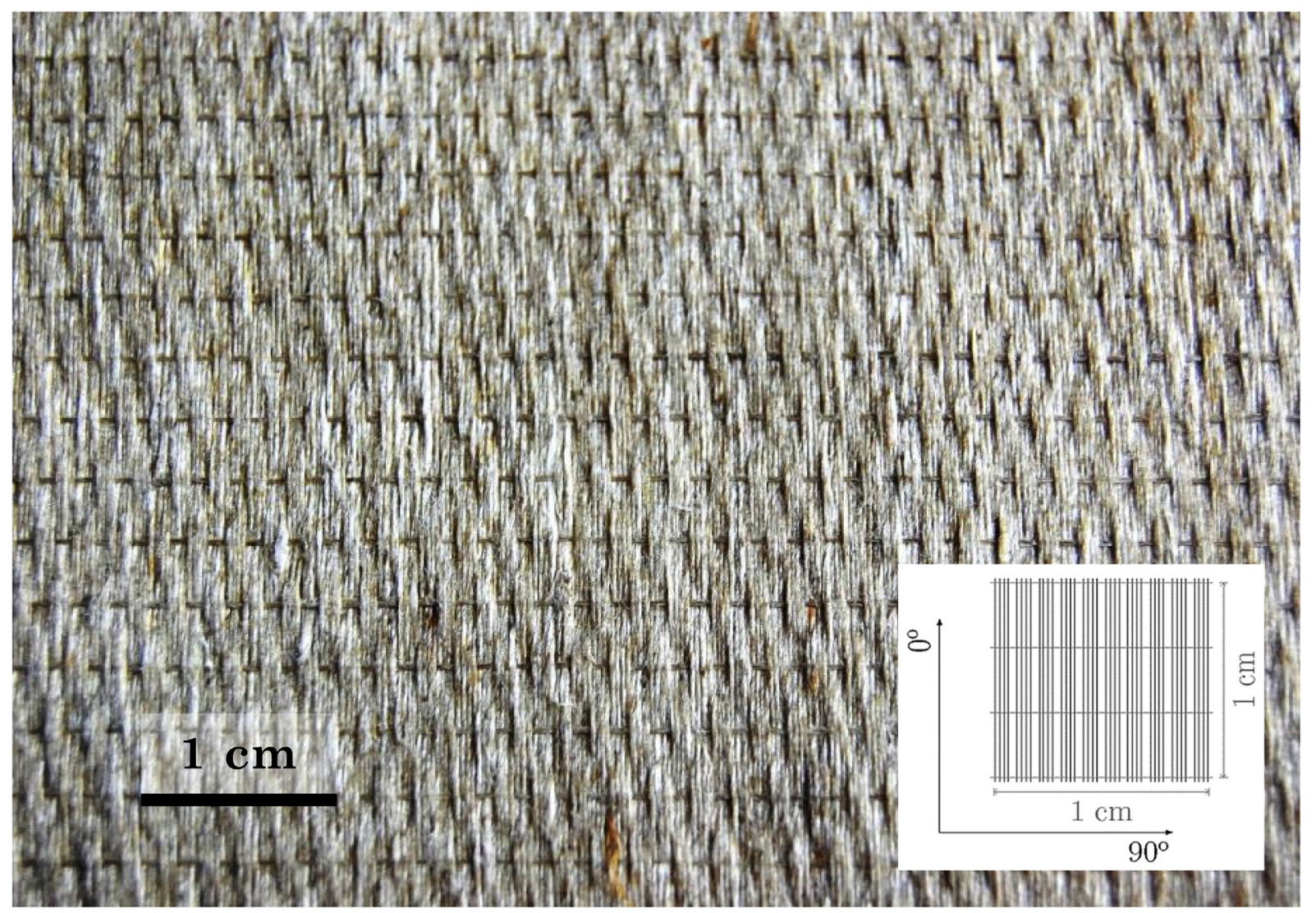

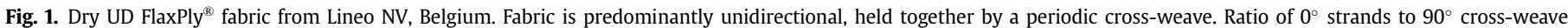
strands is $40: 3$.

is a twisted bundle of elementary fibres with a bundle diameter of $\sim 150-300 \mu \mathrm{m}$ (Fig. 2). Note that, while the fabric is not perfectly unidirectional (due to the presence of cross-weave strands), a previous study on the same Flax fabric composites [59] showed that the tested mechanical properties compare very well with existing published data on unidirectional continuous-fibre Flax composites - thus indicating that the cross-weaves do not have a significant influence on the bulk composite response, and that the fabric may be considered practically unidirectional in nature.

For the matrix, hot-curing epoxy resin Araldite ${ }^{\circledR}$ LY 1564 and hardener Aradur ${ }^{\mathbb{R}} 22962$ (Huntsman Corporation, The Woodlands, TX, USA) were used. Following supplier recommendation, the epoxy-to-hardener ratio was maintained at $4: 1$ by weight. Specimen plates were manufactured by hand-layup of Flax fibres soaked in the epoxy-hardener mixture, followed by a heated platen press consolidation procedure (Fig. 3(a)). The Flax fabric was not subjected to any treatment before composite manufacture. The cure cycle began at $120^{\circ} \mathrm{C}$ for $15 \mathrm{~min}$ followed by $150^{\circ} \mathrm{C}$ for $2 \mathrm{~h}$, resulting in a glass transition temperature $\left(T_{g}\right)$ of $130-140{ }^{\circ} \mathrm{C}$ per supplier specifications.

All manufactured plates were around $4 \mathrm{~mm}$ thick. Since conventional techniques of estimating volume fraction (e.g. per ASTM D3171) involve matrix digestion or matrix burn-off processes that will severely degrade organic fibres, such methods are unsuitable for plant fibre composites. Considering this, the constituent fractions were determined using an optical method whereby SEM cross-section images are examined using image analysis software to estimate area fractions of fibre, matrix, and void regions. The area fractions thus determined are considered to be representative of the volume content. Details of this method can be found in Ref. [59] where the same Flax-epoxy composites were studied. Random measurements of manufactured samples indicated an average fibre volume fraction of $49.6 \% \pm 2.3$, and void content of $3.3 \% \pm 3.0$. Rectangular $250 \times 25 \mathrm{~mm}$ specimens (Fig. 3(b)) were cut from manufactured plates by fine-cutting diamond-edge saw, followed by edge grinding for a flat finish. Specimens were tabbed with $64 \mathrm{~mm}$ tapered aluminium tabs. The specimen and tab dimensions are within the guidelines of ASTM D3039 [87].

\subsection{Testing}

All tensile tests were conducted at room temperature and pressure conditions in a servo-hydraulic MTS 322 (Eden Prairie, MN, USA) test frame at a displacement rate of $2 \mathrm{~mm} / \mathrm{min}$. Longitudinal strain was measured using a uniaxial extensometer (gauge length $0.5 \mathrm{in}$, or $12.7 \mathrm{~mm}$ ), and transverse strain was measured by a $350 \Omega$ strain gauge. To observe the evolving stiffness of specimens and thereby measure damage progression, repeated cycles of loading and unloading are imposed on specimens at progressively increasing maximum loads until specimen fracture. Fig. 4 shows the evolving stiffness and the inelastic strain measured from a typical cycled load-unload response plot. Note that the hysteretic response can be considered as linear elastic.

\section{Model}

The Mesoscale Damage Theory (MDT) essentially allows prediction of damage and permanent strain development in an elementary ply in a fibre reinforced composite. The ply is considered to be an orthotropic elastic-plastic material that demonstrates 

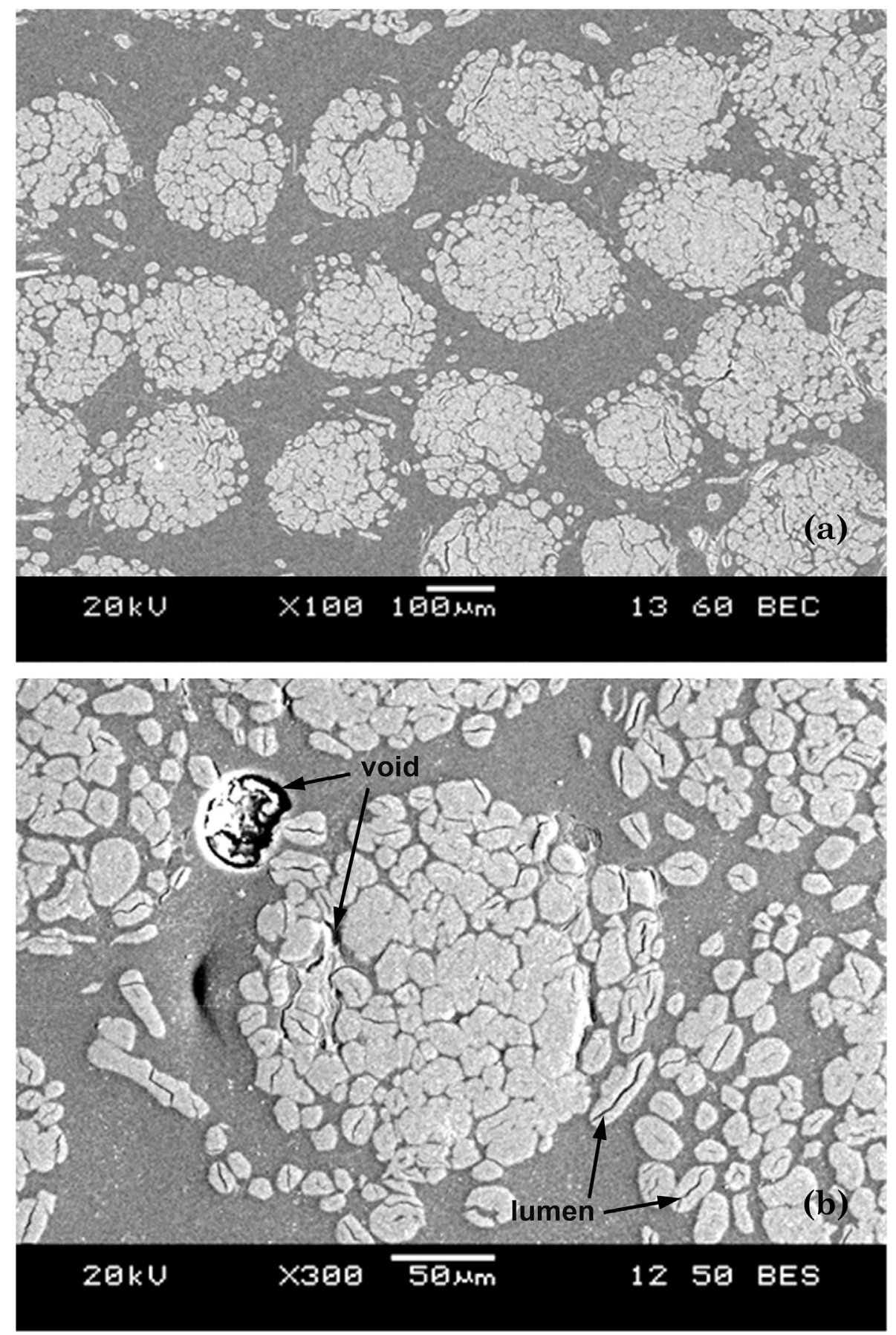

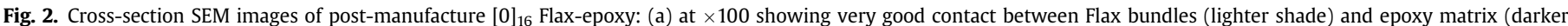
shade); and (b) at $\times 300$ showing porosity, and collapsed lumen within elementary fibres.

deteriorating mechanical properties (reflected in stiffness tensor) due to internal damage under applied loading. It is assumed that the damage events are uniformly distributed through the thickness of a ply, and that the damage state can vary from ply to ply. As will be outlined in the following sections, the damage model is applied for each ply in the laminate being loaded and the resulting global laminate response is determined. A full description of the standard model, including validated examples, can be found in Refs. $[35,68,70]$. Since the standard MDT model assumes a simple linear elastic brittle response in the fibre-direction, therefore unsuitable for modelling NFCs, this study improves the model further by introducing formulations for fibre-direction damage and plasticity, so as to effectively describe the nonlinear NFC response.

\subsection{Mesoscale damage theory preliminaries}

The MDT is developed within the framework of irreversible thermodynamics. Considering that damage and inelasticity effects are observed in the deforming composite, the constitutive model must include both physical processes while satisfying the fundamental postulates of thermodynamics. The Gibbs Free Energy $\mathscr{G}$ is chosen as the thermodynamic potential function to represent the 


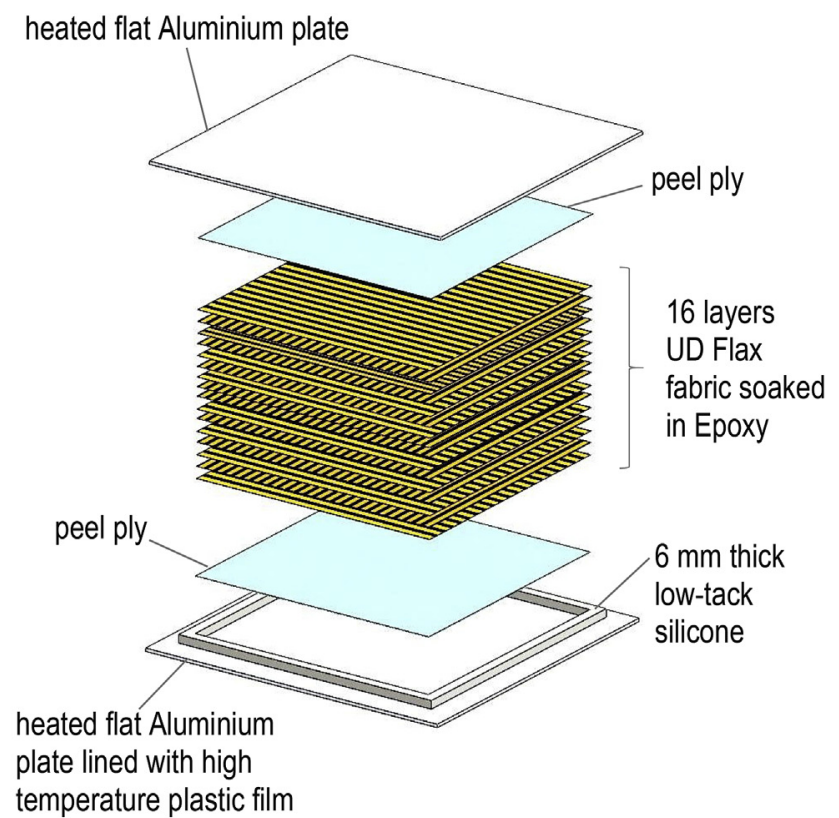

(a)

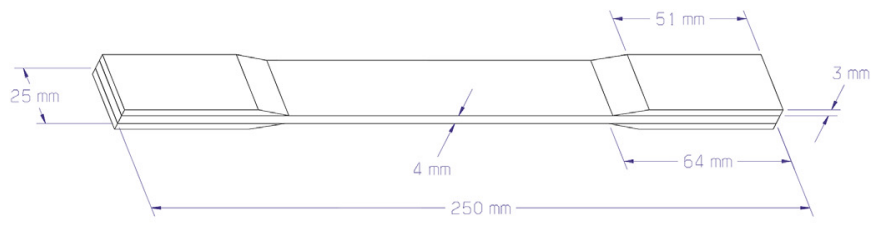

(b)

Fig. 3. (a) Hot platen press consolidation setup for composite plate manufacture, $[0 /$ 90] $]_{4 \mathrm{~S}}$ layup is shown as an example only; (b) Test specimen dimensions.

thermodynamic state of a single ply, expressed as:

$$
\begin{aligned}
\mathscr{G}= & -\frac{1}{2} \boldsymbol{\sigma}: \tilde{\mathscr{L}}^{-1}: \boldsymbol{\sigma}-\boldsymbol{\alpha}: \boldsymbol{\sigma}\left(T-T_{0}\right)+c_{0}\left(\left[T-T_{0}\right]-T \ln \left(\frac{T}{T_{0}}\right)\right) \\
& -s_{0} T+H(\boldsymbol{p})
\end{aligned}
$$

where $\sigma$ is the stress tensor, $\tilde{\mathscr{L}}$ is the stiffness tensor of the damaged material, $\alpha$ is the thermal expansion tensor, $T_{0}$ is the reference temperature, $c_{0}$ is the reference specific latent heat, and $s_{0}$ is the reference specific entropy, $\boldsymbol{p}$ is a set of internal variables related to plasticity mechanisms, and $H(\boldsymbol{p})$ is a set of plastic hardening related functions. Please note that ':' operator implies tensor product, where if $A$ and $x$ are higher- and lower-order tensors, respectively, then $A: x \equiv A x$, and $x: x \equiv x^{\top} x{ }^{1}$

Considering $\boldsymbol{h}(\boldsymbol{p})=\frac{\partial H}{\partial \boldsymbol{p}}$ as the partial derivatives of the plastic hardening function, then based on the framework of generalised standard materials, the stress $\boldsymbol{\sigma}$ and local specific entropy production $\gamma_{l o c}$ can be expressed as [88]:

$\boldsymbol{\sigma}=\tilde{\mathscr{L}}\left(\boldsymbol{\varepsilon}-\boldsymbol{\alpha}\left(T-T_{0}\right)-\boldsymbol{\varepsilon}^{p}\right) ; \quad \gamma_{l o c}=\boldsymbol{\sigma}: \dot{\boldsymbol{\varepsilon}}^{p}-\boldsymbol{h}(\boldsymbol{p}): \dot{\boldsymbol{p}}$

where $\varepsilon^{p}$ is the plastic strain tensor. ${ }^{2}$ Each plastic yield surface

\footnotetext{
${ }^{1}$ For example, operation $\sigma: \tilde{\mathscr{L}}^{-1}: \sigma$ is equivalent to matrix multiplication $\{\boldsymbol{\sigma}\}^{\top}[\tilde{\mathscr{L}}]^{-1}\{\boldsymbol{\sigma}\}$.

2 The time derivative (rate) of any quantity is represented by a dot above.
}

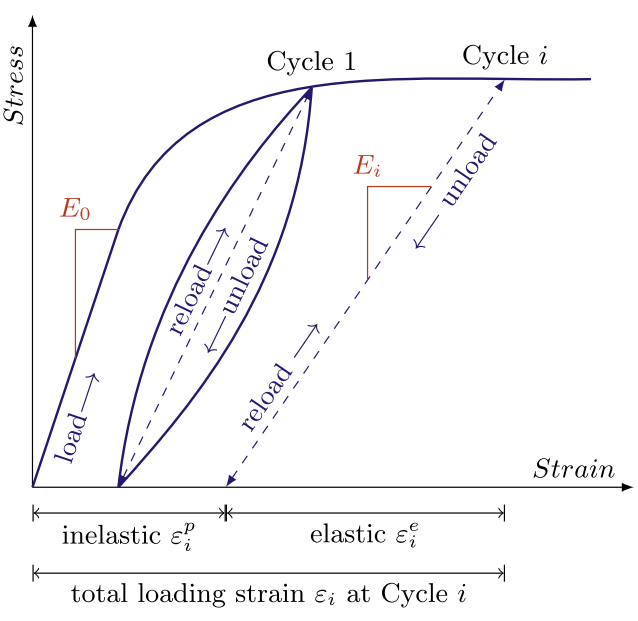

Fig. 4. Typical response under cycled progressive load-unload, showing evolving modulus $E$, elastic strain $\varepsilon^{e}$, and permanent strain $\varepsilon^{p}$.

related to a plasticity mechanism is represented by one internal variable in the set $\boldsymbol{p}$ and defined as a function of the mean stress in the damaged ply. This stress is defined using the stiffness tensor of the damaged material $\tilde{\mathscr{L}}$ :

$\boldsymbol{\sigma}=\tilde{\mathscr{L}}: \boldsymbol{\varepsilon}$

The effective stress state of the material $\tilde{\boldsymbol{\sigma}}$ is defined as follows, at the same strain state:

$\tilde{\boldsymbol{\sigma}}=\mathscr{L}: \boldsymbol{\varepsilon}$

where the effective stress is representative of the actual stress state experienced by the damaged material.

Following (3)-(4), the relationship between ply effective stress $\tilde{\boldsymbol{\sigma}}$ and mean stress $\boldsymbol{\sigma}$ is defined:

$\tilde{\boldsymbol{\sigma}}=\mathscr{\mathscr { L }} \tilde{\mathscr{L}}^{-1}: \boldsymbol{\sigma}$

where the damaged stiffness tensor $\tilde{\mathscr{L}}$ can be expressed by a set of internal damage variables $\boldsymbol{d}=\left[\begin{array}{lll}d_{11} & d_{22} & d_{12}\end{array}\right]^{\top}$ that represents the damage state of the material:

$\tilde{\mathscr{L}}=\tilde{\mathscr{L}}(\boldsymbol{d}, \mathscr{L})$

The elastic constants of the damaged ply formulated as a function of the damage variables are:

$$
\begin{array}{cccccc}
E_{1}=\left(1-d_{11}\right) E_{1}^{0}, & \sigma_{11} \geq 0 ; & \text { otherwise } & E_{1}=E_{1}^{0} \\
E_{2}=\left(1-d_{22}\right) E_{2}^{0}, & \sigma_{22} \geq 0 ; & \text { otherwise } & E_{2}=E_{2}^{0} \\
G_{12}=\left(1-d_{12}\right) G_{12}^{0}, & \sigma_{12} \geq 0 ; & \text { otherwise } & G_{12}=G_{12}^{0}
\end{array}
$$

where $E_{1}, E_{2}$ and $G_{12}$ are the fibre-direction, in-plane transverse, and in-plane shear moduli, respectively. ${ }^{3}$ As for the internal variables, $d_{11}$ quantifies fibre-direction stiffness degradation damage, $d_{22}$ represents in-plane transverse damage, and $d_{12}$ represents inplane shear damage. Accordingly, the initial transversely isotropic behaviour becomes orthotropic when at least one of these damage quantities becomes non-zero.

For a purely mechanical, isothermal deformation process in

\footnotetext{
${ }^{3}$ The superscript notation ${ }^{0}$ indicates initial undamaged moduli, to be determined experimentally.
} 
orthotropic materials, the thermodynamic potential function can be reduced to the elastic strain energy $W_{D}$ expressed in terms of the material properties and damage variables [35,36,68,89]. Assuming that damage affects the elastic energy of a material only in tension: values do not decrease upon unloading, and must remain at the previous peak value until a higher damaging load is applied. We consider damage evolution in the fibre-direction decoupled from transverse and shear damage, so the governing forces for in-plane damage evolution are:

$Y_{f}=\sqrt{Y_{11}}$,

fibre damage, fracture

$Y_{t s}=\sqrt{Y_{12}+b Y_{22}}$, transverse cracking, fibre - matrix debonding

$$
\begin{aligned}
2 W_{D}= & \boldsymbol{\sigma}: \tilde{\mathscr{L}}^{-1}: \boldsymbol{\sigma}=\frac{\left\langle\sigma_{11}\right\rangle_{+}^{2}}{E_{1}^{0}\left(1-d_{11}\right)}+\frac{\left\langle\sigma_{11}\right\rangle_{-}^{2}}{E_{1}^{0}}-\left(2 \frac{\nu_{12}}{E_{1}}\right) \sigma_{11} \sigma_{22} \\
& -\left(2 \frac{\nu_{13}}{E_{1}}\right) \sigma_{11} \sigma_{33}-\left(2 \frac{\nu_{32}}{E_{3}}\right) \sigma_{22} \sigma_{33}+\frac{\left\langle\sigma_{22}\right\rangle_{+}^{2}}{E_{2}^{0}\left(1-d_{22}\right)} \\
& +\frac{\left\langle\sigma_{22}\right\rangle_{-}^{2}}{E_{2}^{0}}+\frac{\sigma_{33}^{2}}{E_{3}}+\frac{\sigma_{12}^{2}}{G_{12}^{0}\left(1-d_{12}\right)}+\frac{\sigma_{13}^{2}}{G_{13}}+\frac{\sigma_{23}^{2}}{G_{23}}
\end{aligned}
$$

where, following [35], it is assumed that the ratios $\frac{\nu_{12}}{E_{1}}=\frac{\nu_{21}}{E_{2}}, \frac{\nu_{13}}{E_{1}}=\frac{\nu_{31}}{E_{3}}$, where $b$ is a transverse-shear damage coupling parameter (to be determined) to express the relative effect of shear and transverse stresses on the fibre-matrix debonding mechanism; and subscripts $f, t \& s$ denote fibre-direction, transverse, and shear, respectively.

From tensile tests on $[0]_{16}$ Flax/epoxy specimens, the fibredirection damage was observed to follow an exponential profile, approaching a limiting value of 0.2 before specimen fracture (Fig. 5(a)). For transverse and shear damage, the standard MDT linear evolutions were found to adequately describe Flax/epoxy damaged response. Therefore, the following set of damage evolution functions is proposed:

$$
\boldsymbol{\Phi}_{d}=\left\{\begin{array}{l}
\left.\Phi_{d_{11}}=d_{\lim }\left[1-\exp \frac{Y_{f}^{0}-Y_{f}}{m}\right)\right]-d_{11}, \quad \text { while } \quad \varepsilon_{11}<\varepsilon_{11}^{\max } ; \quad \text { otherwise } \quad d_{11}=1 \\
\Phi_{d_{22}}=\frac{\left\langle Y_{t s}-Y_{t}^{0}\right\rangle_{+}}{Y_{t}^{c}}-d_{22}, \quad \text { while } \quad d_{22}<1, \quad Y_{22}<Y_{22}^{\max }, \quad Y_{12}<Y_{12}^{\max } ; \quad \text { otherwise } d_{22}=1 \\
\Phi_{d_{12}}=\frac{\left\langle Y_{t s}-Y_{s}^{0}\right\rangle_{+}}{Y_{s}^{c}}-d_{12}, \quad \text { while } \quad d_{12}<1, \quad Y_{22}<Y_{22}^{\max }, \quad Y_{12}<Y_{12}^{\max } ; \quad \text { otherwise } \quad d_{12}=1
\end{array}\right.
$$

and $\frac{\nu_{32}}{E_{3}}=\frac{\nu_{23}}{E_{2}} ;$ and:

$$
\begin{array}{lllll}
\langle a\rangle_{+}=a & \text { if } \quad a \geq 0 ; & \text { otherwise } & \langle a\rangle_{+}=0 \\
\langle a\rangle_{-}=a & \text { if } \quad a \leq 0 ; & \text { otherwise } & \langle a\rangle_{-}=0
\end{array}
$$

Unlike the fully linear-elastic, brittle fibre material assumed in typical MDT models, experimental tests conducted for this study confirm that Flax-composites exhibit progressive damaging behaviour (modulus degradation) in the fibre-direction. The thermodynamic force conjugates for all in-plane internal damage variables in a single ply are therefore derived:

$$
\begin{aligned}
& Y_{11}=\frac{\partial W_{D}}{\partial d_{11}}=\frac{1}{2} \frac{\left\langle\sigma_{11}\right\rangle_{+}^{2}}{E_{1}^{0}\left(1-d_{11}\right)^{2}} \\
& Y_{22}=\frac{\partial W_{D}}{\partial d_{22}}=\frac{1}{2} \frac{\left\langle\sigma_{22}\right\rangle_{+}^{2}}{E_{2}^{0}\left(1-d_{22}\right)^{2}} \\
& Y_{12}=\frac{\partial W_{D}}{\partial d_{12}}=\frac{1}{2} \frac{\sigma_{12}^{2}}{G_{12}^{0}\left(1-d_{12}\right)^{2}}
\end{aligned}
$$

\subsubsection{Damage evolution}

Since the ply material is considered 'non-healing', damage with the following Kuhn-Tucker conditions:

$\Phi_{d_{i j}} \leq 0, \quad \dot{d}_{i j} \geq 0, \quad \Phi_{d_{i j}} \dot{d}_{i j}=0 ; \quad$ for $\quad i, j \in\{1,2\}$

where $\Phi_{d_{i j}}$ is the damage function for the corresponding damage variable $d_{i j}, \varepsilon_{11}^{\max }$ is the fibre-direction ultimate strain, while $m, d_{\text {lim }}$, $Y_{f}^{0}, Y_{t}^{0}, Y_{t}^{c}, Y_{s}^{0}, Y_{s}^{c}, Y_{22}^{\max }$, and $Y_{12}^{\max }$ are parameters to be determined; and $\langle\ldots\rangle_{+}$is defined earlier in (9).

A damage value of $d_{i j}=1$ indicates a complete loss of stiffness in plane $i j$. Note that both transverse and shear damage evolutions as defined in (12) are not influenced by fibre-direction parameters i.e. the fibre-direction damage remains fully decoupled from transverse-shear in our proposed model.

\subsubsection{Inelasticity evolution}

As discussed earlier, Flax-composites have been shown to develop permanent strains when loaded beyond a threshold limit. The standard MDT formulation [35,70] is adapted here to simulate inelasticity in NFCs, wherein the total strain in any orthotropic direction is decomposed into elastic and inelastic components:

$\dot{\varepsilon}_{i j}=\dot{\varepsilon}_{i j}^{e}+\dot{\varepsilon}_{i j}^{p}, \quad$ for $\quad i, j \in\{1,2\}$

where $e$ and $p$ represent elastic and inelastic components, 
respectively.

Effective inelastic strain rates are defined in terms of damage:

$\dot{\tilde{\varepsilon}}_{i j}^{p}=\dot{\varepsilon}_{i j}^{p}\left(1-d_{i j}\right), \quad$ for $\quad i, j \in\{1,2\}$

A set of yield surfaces (or elastic domain functions) $\boldsymbol{\Phi}^{p}=\left[\begin{array}{ll}\Phi_{f}^{p} & \Phi_{t s}^{p}\end{array}\right]^{\top}$ is defined for fibre-direction and coupled transverse-shear plasticity evolutions, respectively. To formulate the transverse-shear yield surface $\Phi_{t s}^{p}$, the standard MDT assumes a Mises-type coupling between the transverse and shear effective stresses [35,68], with the hardening assumed to be isotropic and governed by a power law. Unlike in typical MDT-based models, a fibre-direction plasticity evolution $\Phi_{f}^{p}$ is also introduced here since natural fibres demonstrate considerable inelastic behaviour [8]. The fibre-direction response is still assumed decoupled from the other in-plane deformations similar to the standard model, and the fibredirection hardening also appears to follow a power law based on experimental observations (Fig. 5(b)).

We consider $\boldsymbol{\Phi}^{p}$ having the following form, along with the Kuhn-Tucker conditions:

$$
\begin{aligned}
& \Phi_{f}^{p}=\tilde{\sigma}_{f}^{e q}-h_{f}\left(\tilde{p}_{f}\right)-\sigma_{f}^{0} \leq 0, \quad \dot{p}_{f} \geq 0, \quad \Phi_{f}^{p} \dot{p}_{f}=0 \\
& \Phi_{t s}^{p}=\tilde{\sigma}_{t s}^{e q}-h_{t s}\left(\tilde{p}_{t s}\right)-\sigma_{t s}^{0} \leq 0, \quad \dot{p}_{t s} \geq 0, \quad \Phi_{t s}^{p} \dot{p}_{t s}=0
\end{aligned}
$$

where function $\Phi_{f}^{p}$ represents the inelastic behaviour in the fibredirection, $\Phi_{t s}^{p}$ represents coupled in-plane transverse-shear response; $\sigma_{f}^{0}$ and $\sigma_{t s}^{0}$ are plasticity initiation parameters to be determined; $h_{f}$ and $h_{t s}$ are hardening functions that are dependent on accumulated effective inelastic strains: fibre-direction represented by $\tilde{p}_{f}$, and $\tilde{p}_{t s}$ represents equivalent transverse-shear (similar to that defined in standard MDT model $[35,68,70])$. As noted earlier, both hardening functions can be described as power laws:

$h_{f}\left(\tilde{p}_{f}\right)=\beta_{f}\left(\tilde{p}_{f}\right)^{\alpha_{f}}$
$h_{t s}\left(\tilde{p}_{t s}\right)=\beta_{t s}\left(\tilde{p}_{t s}\right)^{\alpha_{t s}}$

where $\beta_{f}, \alpha_{f}, \beta_{t s}$, and $\alpha_{t s}$ are all parameters to be identified. Equivalent stresses $\tilde{\sigma}_{f}^{e q}$ and $\tilde{\sigma}_{t s}^{e q}$ are scalars that influence plasticity in the fibre-direction and transverse-shear, similar to that in standard MDT [35,68,70]:

$$
\begin{aligned}
& \tilde{\sigma}_{f}^{e q}=\frac{\sigma_{11}}{\left(1-d_{11}\right)} \\
& \tilde{\sigma}_{t s}^{e q}=\sqrt{\frac{\sigma_{12}^{2}}{\left(1-d_{12}\right)^{2}}+A_{t s} \frac{\sigma_{22}^{2}}{\left(1-d_{22}\right)^{2}}}
\end{aligned}
$$

In our numerical implementation, the above relationships (18) are achieved by defining $\tilde{\sigma}_{f}^{e q}$ and $\tilde{\sigma}_{t s}^{e q}$ as the von Mises equivalents of all $n$ components in, respectively, vectors $\tilde{\boldsymbol{\sigma}}^{f}$ and $\tilde{\boldsymbol{\sigma}}^{t s}$ :

$$
\begin{aligned}
& \tilde{\sigma}_{f}^{e q}=\sqrt{\sum_{i=1}^{n}\left\{\tilde{\sigma}_{i}^{f}\right\}^{2}} \\
& \tilde{\sigma}_{t s}^{e q}=\sqrt{\sum_{i=1}^{n}\left\{\tilde{\sigma}_{i}^{t s}\right\}^{2}}
\end{aligned}
$$

where vectors $\tilde{\boldsymbol{\sigma}}^{f}$ and $\tilde{\boldsymbol{\sigma}}^{\text {ts }}$ are linear map transformations of effective stress vector $\tilde{\boldsymbol{\sigma}}$ :

$$
\begin{aligned}
& \tilde{\boldsymbol{\sigma}}^{f}=\boldsymbol{\Theta}^{f}: \tilde{\boldsymbol{\sigma}} \\
& \tilde{\boldsymbol{\sigma}}^{t s}=\boldsymbol{\Theta}^{t s}: \tilde{\boldsymbol{\sigma}}
\end{aligned}
$$

where $\Theta^{f}$ and $\boldsymbol{\Theta}^{t s}$ are transformation tensors with the components:

$$
\begin{array}{llll}
\Theta_{1111}^{f} & =1, & \text { otherwise } & \Theta_{i j k l}^{f}=0 \\
\Theta_{2222}^{t s} & =A_{t s}, \quad \Theta_{1212}^{t s}=1, & \text { otherwise } & \Theta_{i j k l}^{t s}=0
\end{array}
$$

where $A_{t s}$ is a coupling parameter to be identified.

Following the normality condition requirement of classical plasticity, the accumulated plastic strain rate $\dot{\tilde{p}}$ is normal to the elastic domain surface, i.e. it follows the direction of the gradient of the respective yield function $\Phi^{p}$. Therefore, similar to standard MDT [35,68], we derive:

$\dot{\tilde{p}}=\dot{\lambda}, \quad \Lambda=\frac{\partial \Phi^{p}}{\partial \tilde{\sigma}_{i j}}, \quad \dot{\tilde{\varepsilon}}_{i j}^{p}=-\dot{\tilde{p}} \Lambda \quad$ for $\quad i, j \in\{1,2\}$

where $\lambda$ is the plastic multiplier, and $\Lambda$ is the plasticity direction tensor. It follows that:

$$
\begin{aligned}
& \dot{\tilde{\varepsilon}}_{11}^{p}=\dot{\lambda} \frac{\partial \Phi_{f}^{p}}{\partial \tilde{\sigma}_{11}}=\dot{\tilde{p}}_{f} \frac{\tilde{\sigma}_{11}}{\left(h_{f}\left(\tilde{p}_{f}\right)+\sigma_{f}^{0}\right)}=\dot{\tilde{p}}_{f} \\
& \dot{\tilde{\varepsilon}}_{22}^{p}=\dot{\lambda} \frac{\partial \Phi_{t s}^{p}}{\partial \tilde{\sigma}_{22}}=\dot{\tilde{p}}_{t s} \frac{\tilde{\sigma}_{22}}{\left(h_{t s}\left(\tilde{p}_{t s}\right)+\sigma_{t s}^{0}\right)} \\
& 2 \dot{\tilde{\varepsilon}}_{12}^{p}=\dot{\lambda} \frac{\partial \Phi_{t s}^{p}}{\partial \tilde{\sigma}_{12}}=\quad \dot{\tilde{p}}_{t s} \frac{\tilde{\sigma}_{12}}{\left(h_{t s}\left(\tilde{p}_{t s}\right)+\sigma_{t s}^{0}\right)}
\end{aligned}
$$

\subsection{Multi-ply response using periodic homogenisation approach}

To determine the behaviour of multi-ply laminates based on the individual behaviour of each ply, an homogenisation procedure is applied. Although regular multi-ply composites are generally treated using the laminate theory [90], it is convenient to define a homogenisation procedure based on the periodic homogenisation theory. Such an approach, following the principles introduced in the pioneering works of Bensoussan et al. [91] and Sanchez-Palencia [92], can be defined in the case of nonlinear behaviour of the plies and has the advantage to account for 3D loading conditions. This approach has been successfully implemented for composite materials with plies exhibiting a strong non-linear response, such as shape-memory alloy composites [93]. A fully coupled thermomechanical approach has also been recently developed [88], which will be advantageous for further work on coupling between damage and other dissipative processes. Considering the rather important development of irreversible strain in the Flax plies and the stiffness evolution due to damage, the integration of the proposed damage model into an incremental homogenisation strategy is necessary to properly describe the local response of the plies, taking into account internal stresses that might arise due to the inelastic strain mismatch between the plies.

\subsection{Implementation}

The model has been implemented using the open-source 'Smartplus' C ++ libraries (Smart Materials Algorithms and Research Tools), developed by several collaborating laboratories 
and institutions [94]. The mesoscale damage model numerical implementation uses the convex cutting plane algorithm proposed by Simo and Hughes [95]. The system of non-linear equations that arises from the multiple damaging phenomena (damage evolution functions $\boldsymbol{\Phi}_{d}$ and plasticity yield functions $\boldsymbol{\Phi}^{p}$ ) are treated using generic numerical schemes presented in Ref. [88].

The multiscale modelling scheme is summarised as follows:

1 The loading history is transformed into discrete applied stress increments $\Delta \sigma$

2 A material point numerical solver is utilised to predict an increment of strain $\Delta \bar{\varepsilon}$, using the effective tangent modulus of the composite material $\overline{\mathscr{L}}^{t}$

$3 \Delta \bar{\varepsilon}_{r}$ is defined as the strain increment decomposed over each ply $r$ using a localisation equation of the periodic homogenisation method for laminates as presented in Ref. [88]

4 The constitutive model then predicts the evolution of damage, updated mean stress, and the continuum tangent modulus in each ply

5 The periodic homogenisation schemes use the tangent moduli to predict a new localisation of strain increment, or if the periodic homogenisation framework has converged to a solution for the localisation equations, the updated effective stress and effective tangent modulus is computed and returned to the material point solver

6 The process continues until the material point solver converges to match the applied stress increments - in which case, a new increment step begins

\subsection{Identification of model parameters}

All parameters related to damage and plasticity of the proposed model are mainly identified by applying a cost-function minimising optimisation method. The optimisation algorithm searches for parameters that result in predictions that best match experimental observations. Note that, to determine evolution functions for fibredirection damage and inelasticity (equations (12) and (17), an important contribution of this study on NFCs), it was necessary to also conduct experimental methods of identification (shown in Fig. 5), similar to those recommended by publications on standard MDT $[35,68]$.

Due to the inherent non-linear response of the plies, and especially the development of permanent strains, internal stresses due to strain mismatch between the plies may occur and lead to stress states significantly different than those predicted using classical linear elasticity theory. Therefore, the more appropriate method to determine the actual stress/strain state of the plies is to use the incremental multiscale scheme presented earlier. The identification method thus necessitates running the numerical model, since no analytical closed-form solution is available for such nonlinear ply response - or, if one exists, it has not been explored yet due to the extreme dependence of such relations on the constitutive model adopted and composite configurations.

The proposed scheme is an inverse identification procedure based on a hybrid genetic/gradient method [96] that combines an evolutionary/genetic algorithm with the Levenberg-Marquardt algorithm to minimise the cost function. Such a procedure is able to identify material parameters directly from the modelled structure, e.g. a multi-ply composite, that involves different stacking sequences and under loading configurations.

Having a constitutive model with a specific set of material parameters, the identification problem is the determination of parameters that minimise the difference between computed and experimental data. Since an applied stress loading path is used to define the boundary value problem of the multi-ply multiscale model, the resulting strains are utilised to define the cost function to be minimised:

$C(\mathbf{p})=\frac{1}{2} \sum_{i} \frac{1}{N_{i}}\left(v_{i}^{\text {num }}(\mathbf{p})-v_{i}^{\exp }\right)$

where $C(\mathbf{p})$ is the cost function, $v_{i}^{\text {num }}(\mathbf{p})$ is the $i$-th result (longitudinal and transverse strain) obtained with the numerical simulation, $v_{i}^{\exp }$ is the corresponding $i$-th set of experimental data, and $N_{i}$ is a weight factor.

Note that all experimental data are obtained from a number of tests at different times and at different spatial locations. The weight factor is set to automatically consider an equal weighting of all configurations tested:

$$
\begin{aligned}
C(\mathbf{p})= & \frac{1}{2}\left(\frac{\sum_{t} \sum_{\text {stackseq }}\left(\varepsilon_{x x}^{\text {num }}(\mathbf{p})-\varepsilon_{x x}^{\exp }\right)^{2}}{\sum_{t} \sum_{\text {stackseq }}\left(\varepsilon_{x x}^{\exp }\right)^{2}}\right. \\
& \left.+\frac{\sum_{t} \sum_{\text {stackseq }}\left(\varepsilon_{y y}^{\text {num }}(\mathbf{p})-\varepsilon_{y y}^{\exp }\right)^{2}}{\sum_{t} \sum_{\text {stackseq }}\left(\varepsilon_{y y}^{\exp }\right)^{2}}\right)
\end{aligned}
$$

where $\varepsilon_{x x}^{\exp }$ and $\varepsilon_{y y}^{\exp }$ represent the longitudinal and transverse
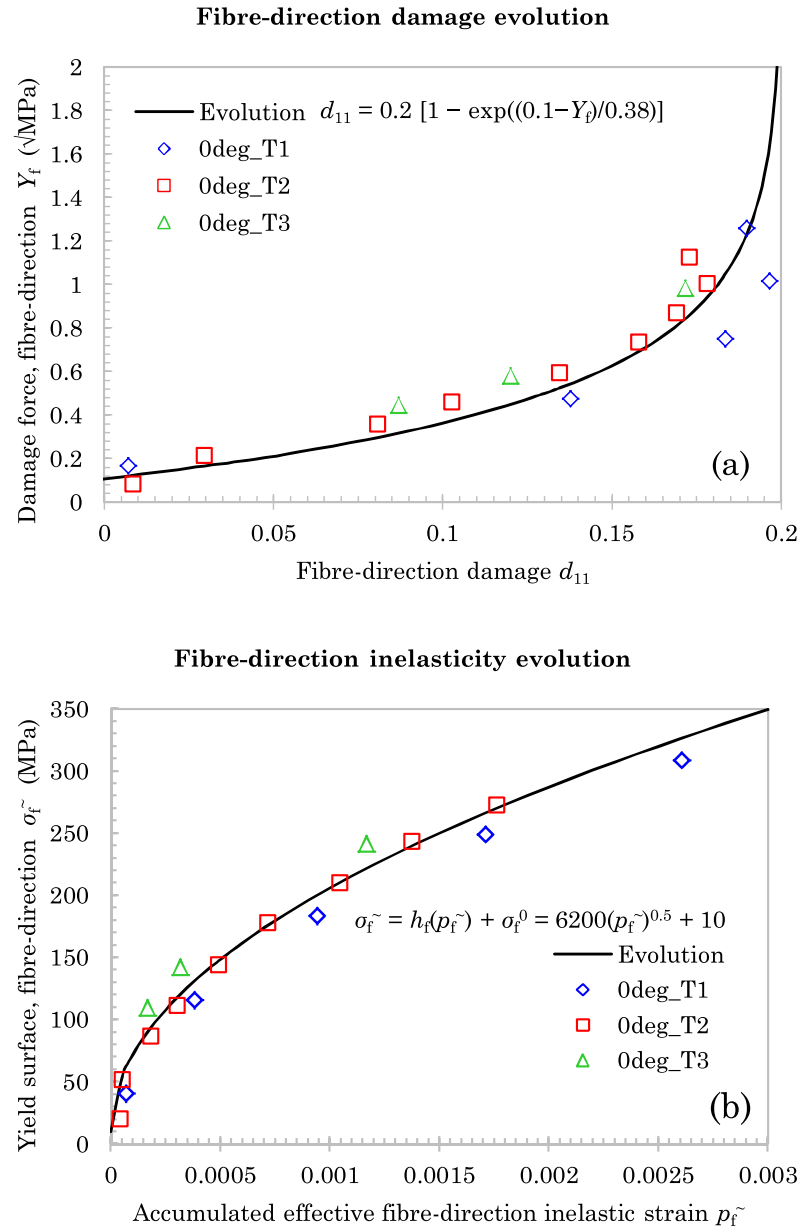

Fig. 5. Fibre-direction evolution laws for tensile (a) damage and (b) inelasticity, as observed from Flax/epoxy $[0]_{16}$ specimens. 
Table 1

Identified model parameters for Flax/epoxy laminate in-plane response.

\begin{tabular}{|c|c|}
\hline \multicolumn{2}{|c|}{ Material properties } \\
\hline$E_{1}^{0}$ & $31 \mathrm{GPa}$ \\
\hline$\varepsilon_{11}^{1}$ & $1.6 \%$ \\
\hline$\nu_{12}^{0}$ & 0.353 \\
\hline$E_{2}^{0}$ & $4.6 \mathrm{GPa}$ \\
\hline$\nu_{21}^{0}$ & 0.063 \\
\hline$G_{12}^{0}$ & $2.0 \mathrm{GPa}$ \\
\hline \multicolumn{2}{|c|}{ Fibre-direction damage } \\
\hline$Y_{f}^{0}$ & $0.1 \sqrt{\mathrm{MPa}}$ \\
\hline$d_{\lim }$ & 0.2 \\
\hline$m$ & $0.38 \sqrt{\mathrm{MPa}}$ \\
\hline \multicolumn{2}{|c|}{ Fibre-direction yield \& inelasticity } \\
\hline$\sigma_{f}^{0}$ & $10 \mathrm{MPa}$ \\
\hline$\alpha_{f}$ & 0.54 \\
\hline$\beta_{f}$ & 6200 \\
\hline \multicolumn{2}{|c|}{ Shear damage } \\
\hline$Y_{12}^{\max }$ & $2.96 \mathrm{MPa}$ \\
\hline$Y_{S}^{0}$ & $0.01 \sqrt{\mathrm{MPa}}$ \\
\hline$Y_{S}^{c}$ & $2.5 \sqrt{\mathrm{MPa}}$ \\
\hline \multicolumn{2}{|c|}{ Transverse coupled damage } \\
\hline$b$ & 14 \\
\hline$Y_{22}^{\max }$ & $1.237 \mathrm{MPa}$ \\
\hline$Y_{t}^{0}$ & $0.51 \sqrt{\mathrm{MPa}}$ \\
\hline$Y_{t}^{c}$ & $6.8 \sqrt{\mathrm{MPa}}$ \\
\hline \multicolumn{2}{|c|}{ Transverse-Shear yield \& inelasticity } \\
\hline$A_{t s}$ & 2.195 \\
\hline$\sigma_{t s}^{0}$ & $16 \mathrm{MPa}$ \\
\hline$\alpha_{t s}$ & 0.16009 \\
\hline$\beta_{t s}$ & 180 \\
\hline
\end{tabular}
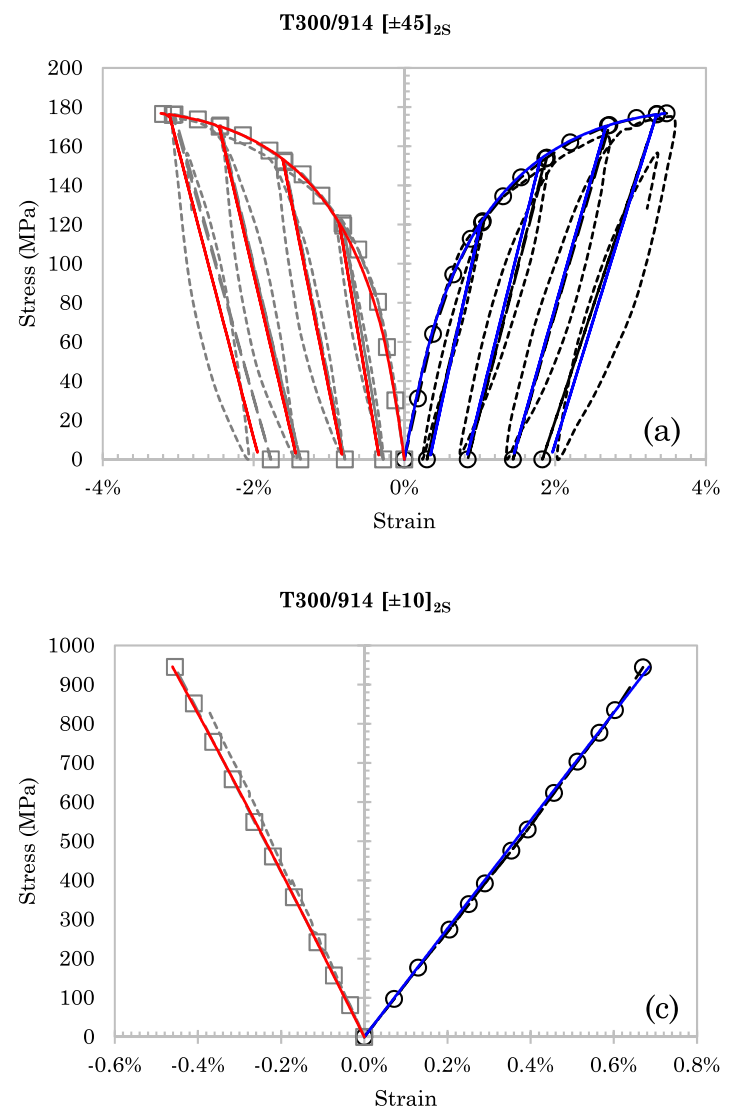

components, respectively, of effective strain at time $t$, from a test performed with ply stacking sequence stackseq; $\varepsilon_{x x}^{\text {num }}$ and $\varepsilon_{y y}^{\text {num }}$ represent the corresponding values computed using the multiscale model; and $\mathbf{p}$ denotes the set of guessed parameters.

Optimisation algorithms must account for local minima, which are expected here considering the presence of multiple nonlinear phenomena. Since gradient-based techniques ensure convergence to a local minima, an heuristic such as genetic algorithm is utilised simultaneously with a gradient-based one, to determine preferential sets of parameters and avoid, as much as possible, convergences to local minima. The identified parameters are all listed in Table 1.

\section{Results, validation and discussion}

The model proposed in this study was executed and the results were validated for both synthetic laminates (T300/914 Carbon/ epoxy) and natural fibre-based laminates (Flax/epoxy).

\subsection{Carbon/epoxy (T300/914)}

To validate the incremental periodic homogenisation scheme integrated in our multi-ply damage model, simulations of stressstrain response for T300/914 Carbon/epoxy laminates with various fibres orientation were compared with standard MDT model predictions and experimental data published by Le Dantec [70] and Ladevèze and Le Dantec [68]. As can be seen in Fig. 6, predictions by our model and those by Ladevèze and Le Dantec are very similar, confirming that the periodic homogenisation-based multi-ply response adopted in this study is robust, in a sense that
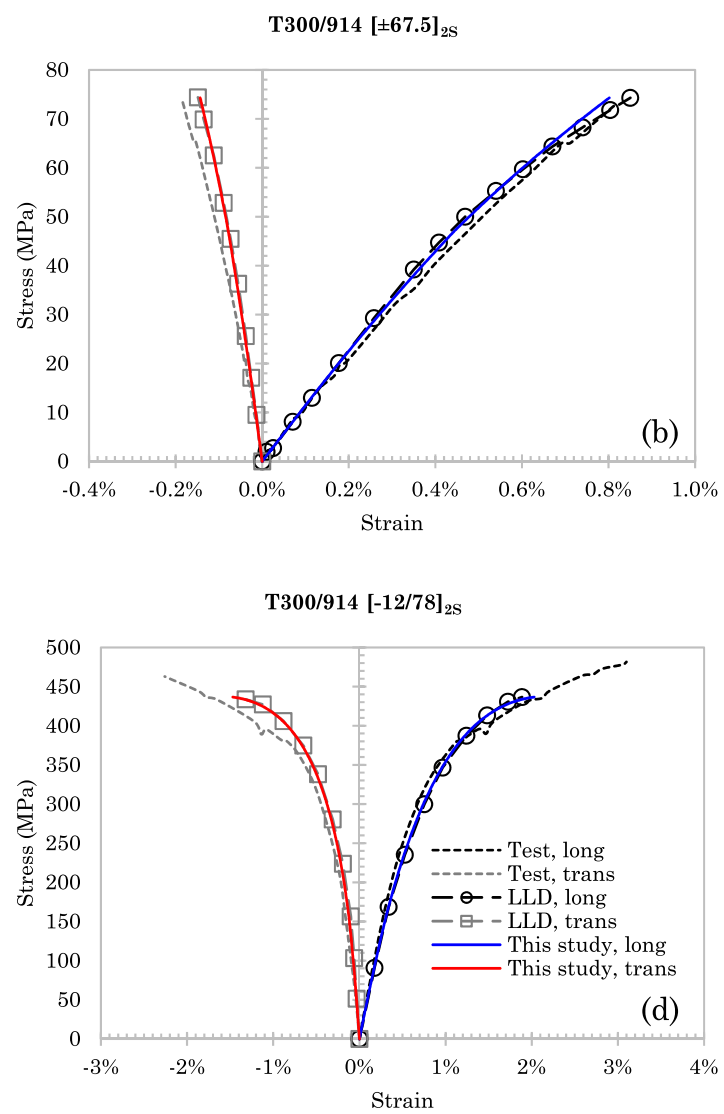

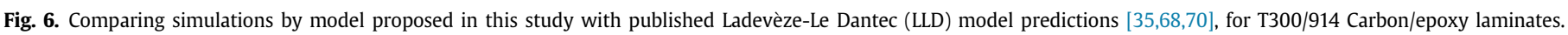
Corresponding test data adapted from Ref. [70]. 

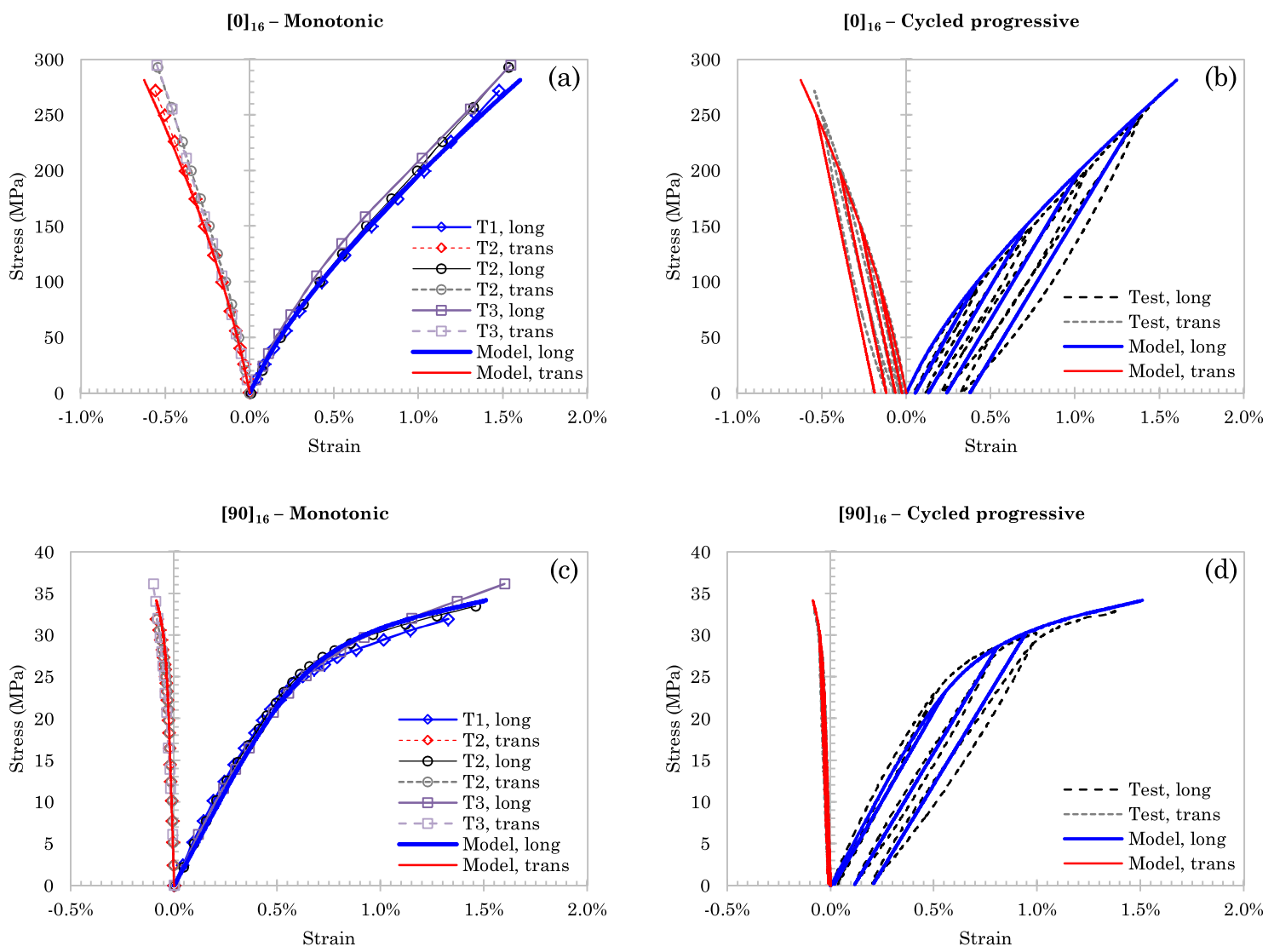

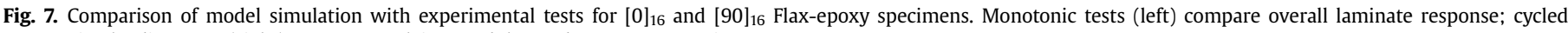
progressive loading tests (right) compare evolving modulus and permanent strain.

it can simulate laminates with a variety of fibre orientations and is also capable of producing reliable damaged response predictions.

Note that such results were obtained using parameters identified using the optimisation algorithm, which thus incorporates the inherent non-linear response of the plies and not the linear elastic approximation present in Ladevèze and Le Dantec [68]. The determination of plies parameters based on the non-linear behaviour of the ply is essential to properly consider the local stress state, which strongly depends on the development of permanent strains and thus the strain mismatch between the plies.

\subsection{Flax/epoxy}

Publications on the standard MDT model recommend cycled load-unload tests on [0], [90], $\left[{ }_{ \pm} 45\right]_{S}$, and $[ \pm 67.5]_{S}$ laminates to determine the material properties and parameter set $[35,68]$. Using the cost-function minimising optimisation method discussed earlier, this study identified parameters for Flax/epoxy laminates based on the tested response of these 'standard' laminates. Cycled progressive loading tests on $[0]_{16}$ provide fibre-direction material properties $\left(E_{1}^{0}, \varepsilon_{11}^{\max } \varepsilon_{11}^{\max }, \nu_{12}^{0}\right)$ and evolution parameters for damage $\left(Y_{f}^{0}, d_{\text {lim }}, m\right)$ and inelasticity $\left(\sigma_{f}^{0}, \alpha_{f}, \beta_{f}\right)$. Tests on $[90]_{16},[ \pm 45]_{4 s}$, and $[ \pm 67.5]_{4 \mathrm{~S}}$ allow identification of in-plane transverse and shear material properties $\left(E_{2}^{0}, \nu_{12}^{0}, G_{12}^{0}\right)$, evolution parameters for sheartransverse coupled damage $\left(Y_{s}^{0}, Y_{s}^{c}, Y_{t}^{0}, Y_{t}^{c}, b, Y_{22}^{\max }, Y_{12}^{\max }\right)$ and inelasticity $\left(\sigma_{t s}^{0}, \alpha_{t s}, \beta_{t s}, A_{t s}\right)$.

At least four cycled progressive loading tests were conducted per laminate. The parameters thus identified are listed in Table 1, and the simulation results for these laminates are plotted along with experimental response in Figs. 7 and 8. Note that, to maintain clarity of demonstration, only one cycled test is shown for each laminate. A very good agreement is observed between experimental and simulated response for most laminates, including predictions of damaged-condition modulus and residual strain (refer back to Fig. 4 for definitions). Fig. 7(a) and (c) compare simulation with tested monotonic response of three specimens each along fibre- and transverse directions, respectively; whereas Fig. 7(b) and (d) make similar comparisons to demonstrate the close agreement of predicted damaged-state modulus $E$ and inelastic strain $\varepsilon^{p}$ at each unload-reload cycle.

Fig. 8 provides similar comparative demonstration for $[ \pm 45]_{4 \mathrm{~S}}$ and $[ \pm 67.5]_{45}$ specimens. Of note is the model prediction for $[ \pm 45]_{4 s}$ : while accurately predicting overall laminate response for most of the loading (see Fig. 8(b)), our model predicts failure at a much lower strain $(\sim 2.5 \%)$ than observed in experimental specimens (9-12\%, see Fig. 8(a)) - but, at a failure stress that matches experiments (75-78 $\mathrm{MPa})$. The simulated response diverges from the experimental after $\sim 1.7 \%$ laminate strain, as seen when comparing plots in Fig. 8(a). The apparent ductile response and large strains observed in tested $[ \pm 45]_{S}$ specimens is welldocumented for Flax-epoxy [56,57,59], and is attributed to the rotation of plies towards the loading axis. The model prediction begins to diverge at around the same loading point at which plyrotation is found to initiate, which is expected since the model continues to enforce $\mathrm{a} \pm 45^{\circ}$ fibre angle and does not account for any reorientation before failure. The same discrepancy between experimental and simulated Flax-epoxy $[ \pm 45]_{S}$ response was also observed and discussed by Andersons et al. [62].

The good agreement between tested and simulated response 

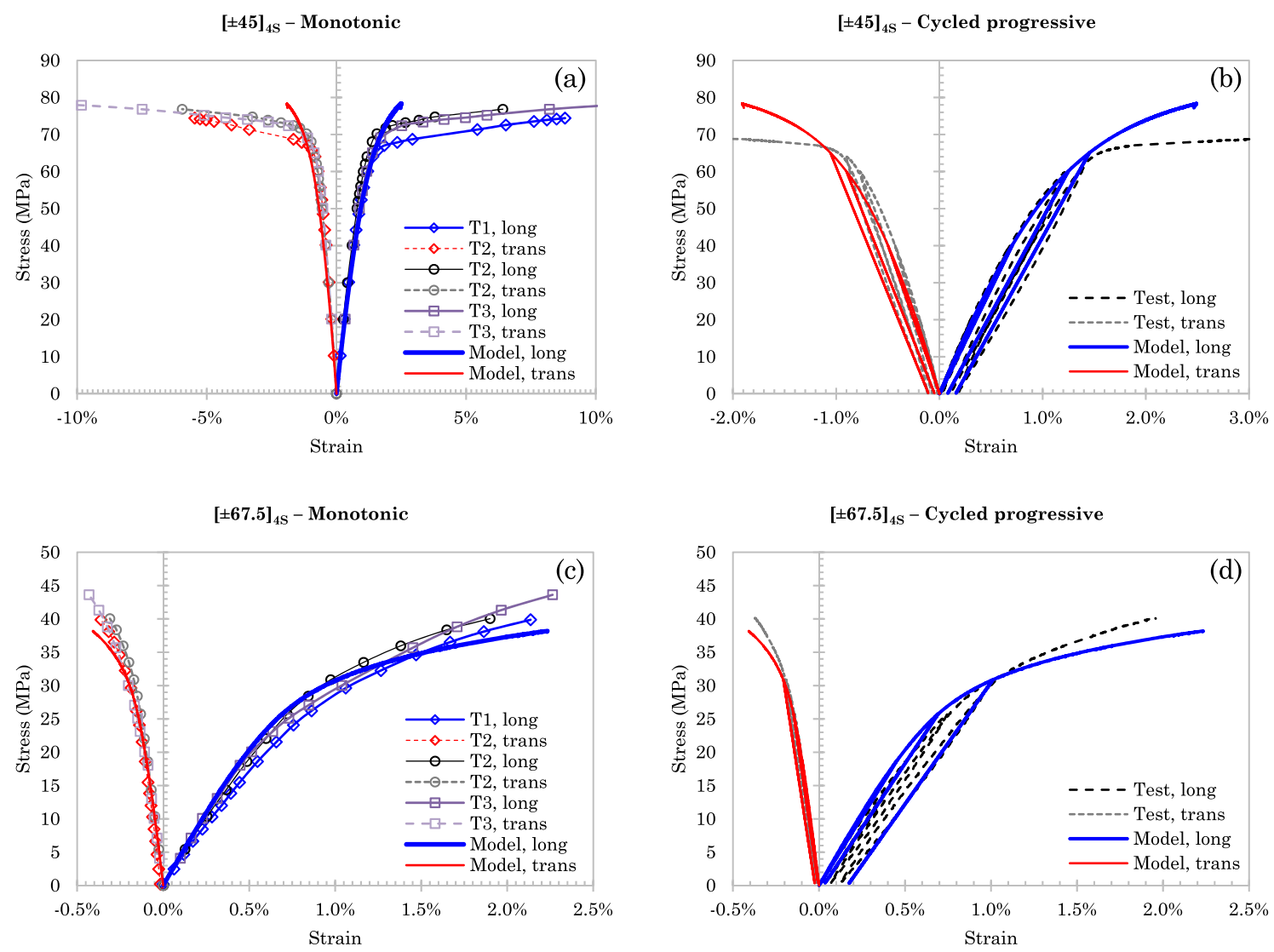

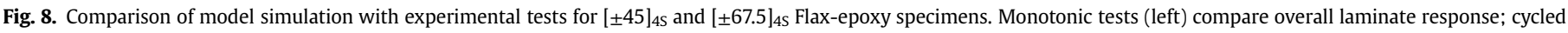
progressive loading tests (right) compare evolving modulus and permanent strain.

confirms that the damage and inelasticity evolution laws developed for our modified-MDT model $\left(\Phi_{d}\right.$ and $\left.\Phi^{p}\right)$, including those proposed for the decoupled fibre-direction (Fig. 5), are appropriately formulated to simulate NFC in-plane tensile response. To further demonstrate the predictive power of the proposed modified-MDT model, numerical simulation is executed for other commonlystudied laminates: angle-ply $[45]_{16}$, cross-ply [0/90 $]_{45}$, and quasiisotropic $[0 /-45 / 90 /+45]_{25}$; shown in Fig. 9. As can be seen, the numerical simulations continue to be in close agreement with tested observations, thus indicating that the multi-ply damaged response model developed in this study is flexible and predictive.

\subsection{Further discussion}

The ply-level, or mesoscale, is chosen to be the basic scale of modelling, since quantification of the internal damaged state is still possible at this scale (via mean ply damage and plasticity state variables), unlike at the laminate scale (macroscale), without sacrificing computational simplicity as in the case with micromechanical modelling. Our modification to the standard MDT proposes nonlinear stiffness degradation and permanent strain accumulation for both fibre-direction and coupled transverse-shear response, where the evolution laws for each are formulated based on experimental observations of NFCs - particularly Flax/epoxy laminates. The unique damage and inelasticity parameters assigned for each in-plane principal direction allows the orthotropic damage effects within each ply to be followed separately. Insight can thus be obtained on the contribution of each variable to the ply response, and subsequently, the contribution of each ply to the mechanical health of the overall laminate under loading.

As the global laminate mechanical response is a function of the plies within, a multi-scale periodic homogenisation scheme (presented in Refs. [88,93]) is adopted to derive the laminate mechanical properties from the individual ply damaged response. An inverse method (cost-function minimisation approach) is applied to identify model parameters specifically for a continuous Flax fibre reinforced epoxy composite. As can be clearly observed from the numerical simulation plots in Figs. 6-9, the modified-MDT model is able to well simulate the damaged modulus and inelastic strain, and thereby predict the complex nonlinear NFC laminate response. In addition, the identified Flax-specific parameters result in predictions that closely match experimental observations (Figs. 7-9).

\subsubsection{Scope for model expansion}

A notable feature of our proposed model is that it does not employ a separate 'interface' layer, as is considered by many MDTbased laminate damage models [71,81,83], since a ply-layer-only model is able to well capture the tensile response of Flax/epoxy NFCs considered in this study (see Figs. 6-9) without the additional complexity of an interface model. If inter-ply delamination mechanisms are of interest, an interface layer may be incorporated by following the approach shown in Refs. [71,83,89,97]. A limitation of our mesoscale model is that, while multiple damage mechanisms may contribute towards stiffness degradation along a particular direction, all such mechanisms are expressed by only a single damage variable, so the model does not distinguish each distinct damage type at the constituent level. For instance, fibre-direction damage involves both cracking in the Flax fibre cell walls, and 
$[45]_{16}-$ Monotonic

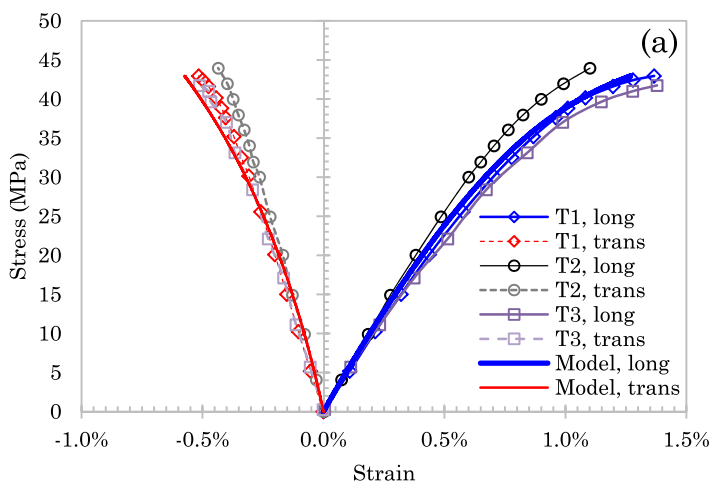

$[0 / 90]_{4 S}-$ Monotonic

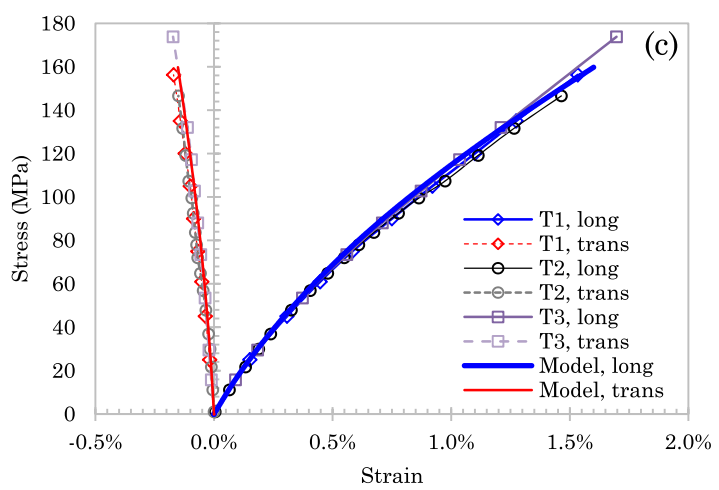

Quasi-Isotropic $[0 /-45 / 90 / 45]_{2 S}-$ Monotonic

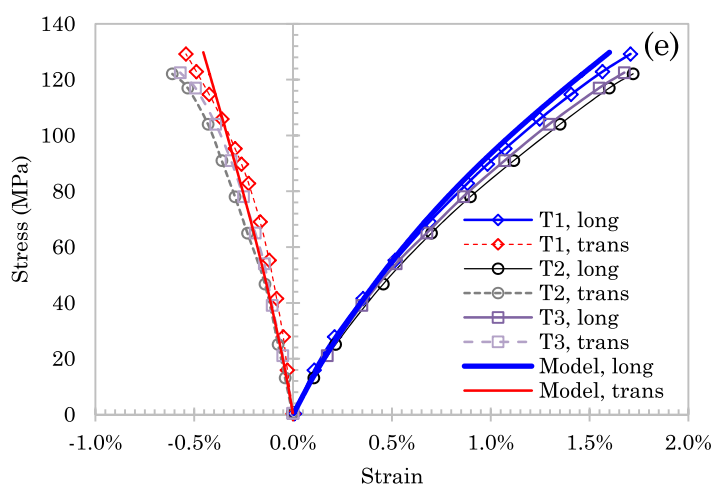

$[45]_{16}$ - Cycled progressive

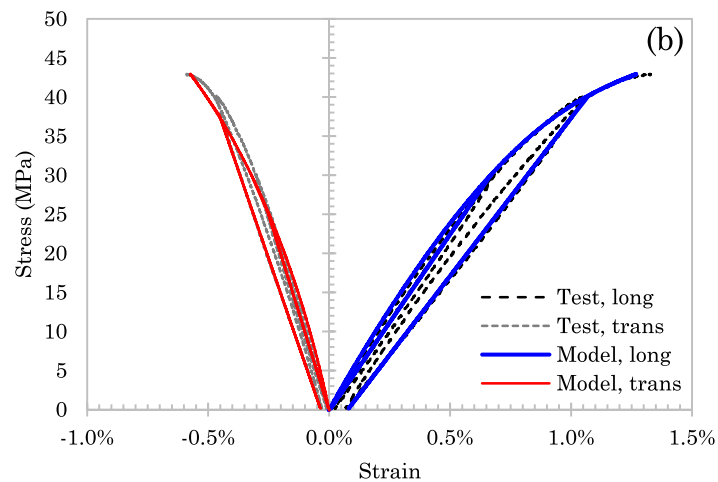

$[0 / 90]_{4 S}-$ Cycled progressive

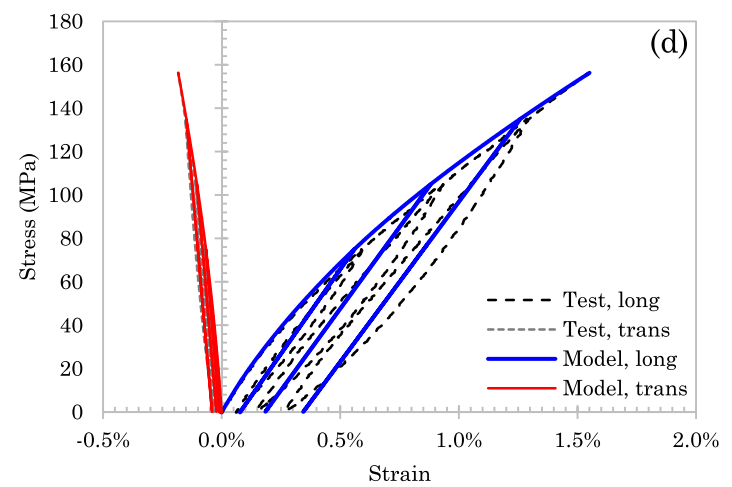

Quasi-Isotropic $[0 /-45 / 90 / 45]_{2 S}-$ Cycled progressive

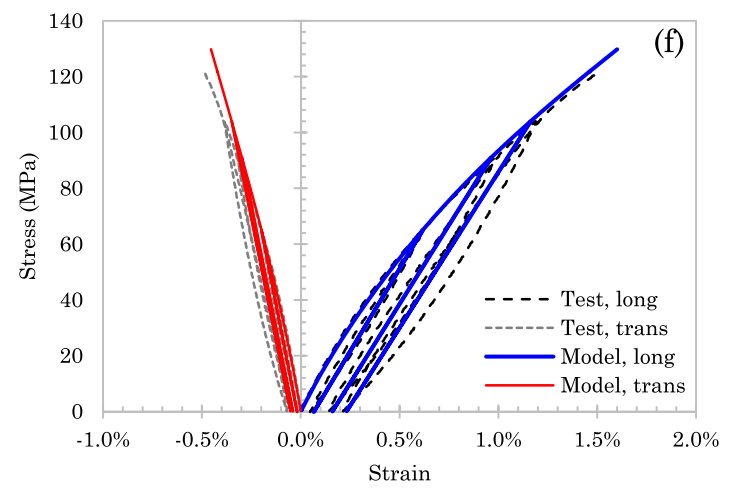

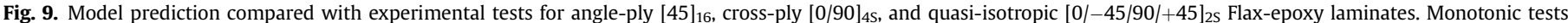
(left) compare overall laminate response; cycled progressive loading tests (right) compare evolving modulus and permanent strain.

separation of elementary fibres due to breakdown in the pectin adhesion $[40,50]$; however, both are represented by only the single variable $d_{11}$ in our model. If separate quantification of individual damage mechanisms is desired, a micromechanical model may be necessary where each contributing damage mode is assigned a unique damage variable and evolution law, similar in approach to that in Ref. [67].

Reported creep tests have confirmed the viscous nature of NFC response [66]. If isolating viscoelastic or viscoplastic response is of interest, the inelastic dissipation in our proposed model may be reformulated similar to that proposed by Poilâne et al. [66], where the total strain is split into elastic, viscoelastic and viscoplastic components, with experimentally-vetted plasticity evolution laws defined to allow kinematic hardening. The same study also demonstrated a marked dependence of NFC fibre-direction response on operating temperature and rate of applied strain. Fig. 10, adapted from the work of Poilâne et al. [66], reveals an inverse relationship between fibre-direction material properties (modulus, strength) and rate of applied strain, as well as operating temperature; however, with insignificant (or inconclusive) effect of either factor on failure strain. Such dependence on strain rate or temperature is also probable for transverse or shear response. As far as fibre-direction response is concerned, correlation with strain rate appears to be roughly proportional on a logarithmic scale (Fig. 10(a)), i.e. the reduction in modulus or failure stress is about the same for each strain rate increase of one order of magnitude. The temperature relationship does not appear to be proportional from the data available (Fig. 10(b)), but it must be noted that, since 

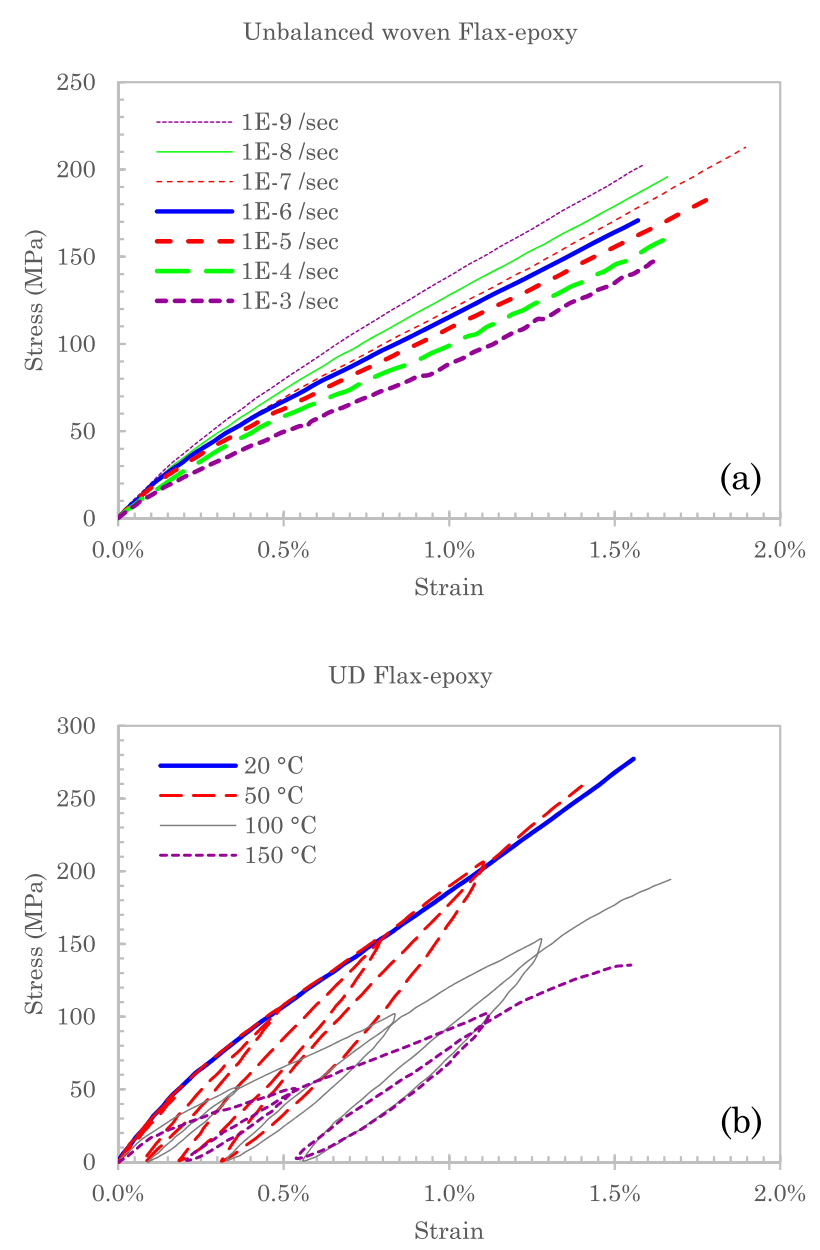

Fig. 10. (a) Unbalanced-fabric Flax-epoxy response in fibre-dominant direction at different applied strain rates, and (b) UD Flax-epoxy fibre-direction response at different ambient temperatures; both figures adapted from Ref. [66].

the source authors Poilâne et al. [66] reported only one test per operating temperature, the data is insufficient to conclusively determine a trend. However, it may be safe to accept that there is no apparent effect on material response between 20 and $50{ }^{\circ} \mathrm{C}$, after which there is significant reduction in both strength and modulus. This reduction in fibre-direction properties may be due to a possible 'softening' in fibre structure, and due to transition of the epoxy matrix from a hard, glassy state to a rubbery state (the epoxy-hardener combination reported in Ref. [66] has a glass transition temperature $T_{g}=\sim 140^{\circ} \mathrm{C}$, per manufacturer datasheet).

In our study, the parameter set identified for Flax/epoxy is for response under a $2 \mathrm{~mm} / \mathrm{min}$ strain rate, at laboratory room temperature $\sim 20^{\circ} \mathrm{C}$. To apply our model for different loading rates or temperature conditions (at least for $>50{ }^{\circ} \mathrm{C}$ ), the fibre-direction damage parameters may need to be re-identified. Alternatively, if identifying new parameter sets is inconvenient: considering that failure strain remains uninfluenced while modulus and failure stress is affected, and assuming that the identified damage evolution laws in Equation (12) still hold true, dependence on strain rate or temperature may be modelled by applying appropriate 'scale factors' to scale up or down the simulated modulus $E$ (Equation (7)) - similar to the approach used in Ref. [97]. To expand the model further for in-plane transverse and shear response at different strain rates or temperatures, the relevant damage and inelastic evolution laws can be re-examined and, if necessary, re-formulated based on experimental observation.

\section{Conclusion}

In summary, this study adopts a thermodynamically consistent Continuum Damage Mechanics (CDM) based approach to develop a predictive model for tensile response in natural fibre reinforced composites (NFC). On account of fibre-specific damage mechanisms unique to hierarchical fibrous structures like plant fibres, NFCs tend to exhibit considerable nonlinearity in their fibre-direction response (unlike traditional Glass or Carbon fibre composites) which is accounted for in the damage model developed in this study in the form of nonlinear evolutions of stiffness and inelasticity. The effect of well-known NFC damage mechanisms (fibre cell-wall cracking, axial splitting of fibre bundles, fibre-matrix debonding, matrix damage, and inelasticity) are captured through the state variables for damage and inelastic dissipation, defined along the lines of standard Mesoscale Damage Theory (MDT) first introduced by Ladevèze and Le Dantec [68,70], and elaborated by Herakovich [35]. Experimental observations of continuous Flax fibre reinforced epoxy material are used to develop the model and identify Flax-specific model parameters. The model is found to offer very good predictions of room-temperature tensile response for various Flax/epoxy laminate configurations. Limitations of the model (discussed in the previous section) notwithstanding, our modified-MDT damage model offers a powerful means of capturing damaged mechanical response in multi-ply NFC laminates, and a viable mesoscale alternative to the few macroscale or micromechanical approaches proposed for NFCs to date (reviewed earlier). The damage model and Flax-specific parameters can be incorporated into a user-defined material properties subroutine, e.g. as part of a finite element structural model, thereby enabling the convenient design and development of Flax fibre reinforced load-bearing structures.

\section{Funding}

This research is supported in part by Natural Sciences and Engineering Research Council of Canada - Discovery Grants program (NSERC-DG), funding reference RGPIN 2014-05838.

\section{Conflict of interest}

None declared.

\section{Acknowledgements}

The authors gratefully acknowledge Hunstman Corporation (The Woodlands, TX, USA) for supplying the epoxy resin and accelerator. The authors also thank Mr. Constantin Nicolinco and Mr. Ahmed Sarwar of Ryerson University (Toronto, ON, Canada) for their kind assistance with computational tasks, Dr. Ihab El Sawi for instruction on mechanical testing, and Mr. Roland Pelland of Bombardier Aerospace for technical assistance with composite plate manufacturing.

\section{References}

[1] Corbière-Nicollier T, Gfeller Laban B, Lundquist L, Leterrier Y, Månson JAE, Jolliet $O$. Life cycle assessment of biofibres replacing glass fibres as reinforcement in plastics. Resour Conserv Recy 2001;33(4):267-87. http:// dx.doi.org/10.1016/S0921-3449(01)00089-1.

[2] Joshi SV, Drzal LT, Mohanty AK, Arora S. Are natural fiber composites environmentally superior to glass fiber reinforced composites? Compos Part AAppl S 2004;35(3):371-6. http://dx.doi.org/10.1016/j.compositesa.2003. 09.016.

[3] Le Duigou A, Davies P, Baley C. Environmental impact analysis of the production of flax fibres to be used as composite material reinforcement. J Biobased Mater Bio 2011;5(1):153-65. http://dx.doi.org/10.1166/jbmb. 
2011.1116.

[4] Liang S, Gning P, Guillaumat L. A comparative study of fatigue behaviour of flax/epoxy and glass/epoxy composites. Compos Sci Technol 2012;72(5): 535-43. http://dx.doi.org/10.1016/j.compscitech.2012.01.011.

[5] Shah DU. Natural fibre composites: comprehensive Ashby-type materials selection charts. Mater Des 2014;62:21-31. http://dx.doi.org/10.1016/ j.matdes.2014.05.002.

[6] Wambua P, Ivens J, Verpoest I. Natural fibres: can they replace glass in fibre reinforced plastics? Compos Sci Technol 2003;63(9):1259-64. http:// dx.doi.org/10.1016/S0266-3538(03)00096-4.

[7] Dittenber DB, GangaRao HVS. Critical review of recent publications on use of natural composites in infrastructure. Compos Part A-Appl S 2012;43(8): 1419-29. http://dx.doi.org/10.1016/j.compositesa.2011.11.019.

[8] Faruk O, Bledzki AK, Fink H-P, Sain M. Biocomposites reinforced with natural fibers: 2000 2010. Prog Polym Sci 2012;37(11):1552-96. http://dx.doi.org/ 10.1016/j.progpolymsci.2012.04.003.

[9] Pil L, Bensadoun F, Pariset J, Verpoest I. Why are designers fascinated by flax and hemp fibre composites? Compos Part A-Appl S 2016;83:193-205. http:// dx.doi.org/10.1016/j.compositesa.2015.11.004.

[10] Satyanarayana KG, Arizaga GGC, Wypych F. Biodegradable composites based on lignocellulosic fibers an overview. Prog Polym Sci 2009;34(9):982-1021. http://dx.doi.org/10.1016/j.progpolymsci.2008.12.002.

[11] Bodros E, Pillin I, Montrelay N, Baley C. Could biopolymers reinforced by randomly scattered flax fibre be used in structural applications? Compos Sci Technol 2007;67(34):462-70. http://dx.doi.org/10.1016/j.compscitech.2006. 08.024 .

[12] Cheung H-Y, Ho M-P, Lau K-T, Cardona F, Hui D. Natural fibre-reinforced composites for bioengineering and environmental engineering applications. Compos Part B Eng 2009;40(7):655-63. http://dx.doi.org/10.1016/ j.compositesb.2009.04.014.

[13] Yan L, Chouw N, Jayaraman K. Flax fibre and its composites - A review. Compos Part B-Eng 2014;56:296-317. http://dx.doi.org/10.1016/ j.compositesb.2013.08.014.

[14] Węcławski BT, Fan M, Hui D. Compressive behaviour of natural fibre composite. Compos Part B Eng 2014;67:183-91. http://dx.doi.org/10.1016/ j.compositesb.2014.07.014.

[15] Ng H-M, Sin LT, Tee T-T, Bee S-T, Hui D, Low C-Y, et al. Extraction of cellulose nanocrystals from plant sources for application as reinforcing agent in polymers. Compos Part B Eng 2015;75:176-200. http://dx.doi.org/10.1016/ j.compositesb.2015.01.008.

[16] Stamboulis A, Baillie C, Peijs T. Effects of environmental conditions on mechanical and physical properties of flax fibers. Compos Part A-Appl S 2001;32(8):1105-15. http://dx.doi.org/10.1016/S1359-835X(01)00032-X.

[17] Garkhail SK, Heijenrath RWH, Peijs T. Mechanical properties of natural-fibremat-reinforced thermoplastics based on flax fibres and polypropylene. Appl Compos Mater 2000;7(5-6):351-72. http://dx.doi.org/10.1023/A: 1026590124038.

[18] Xie X, Zhou Z, Jiang M, Xu X, Wang Z, Hui D. Cellulosic fibers from rice straw and bamboo used as reinforcement of cement-based composites for remarkably improving mechanical properties. Compos Part B Eng 2015;78: 153-61. http://dx.doi.org/10.1016/j.compositesb.2015.03.086.

[19] Kim W, Argento A, Lee E, Flanigan C, Houston D, Harris A, et al. High strainrate behavior of natural fiber-reinforced polymer composites. J Compos Mater 2012;46(9):1051-65. http://dx.doi.org/10.1177/0021998311414946.

[20] El-Sabbagh A, Steuernagel L, Ziegmann G, Meiners D, Toepfer O. Processing parameters and characterisation of flax fibre reinforced engineering plastic composites with flame retardant fillers. Compos Part B-Eng 2014;62:12-8. http://dx.doi.org/10.1016/j.compositesb.2014.02.009.

[21] Alix S, Philippe E, Bessadok A, Lebrun L, Morvan C, Marais S. Effect of chemical treatments on water sorption and mechanical properties of flax fibres. Bioresour Technol 2009;100(20):4742-9. http://dx.doi.org/10.1016/ j.biortech.2009.04.067.

[22] Assarar M, Scida D, El Mahi A, Poilâne C, Ayad R. Influence of water ageing on mechanical properties and damage events of two reinforced composite materials: flaxfibres and glassfibres. Mater Des 2011;32(2):788-95. http:/| dx.doi.org/10.1016/j.matdes.2010.07.024.

[23] Hagstrand P-O, Oksman K. Mechanical properties and morphology of flax fiber reinforced melamine-formaldehyde composites. Polym Compos 2001;22(4): 568-78. http://dx.doi.org/10.1002/pc.10560.

[24] Newman RH. Auto-accelerative water damage in an epoxy composite reinforced with plain-weave flax fabric. Compos Part A-Appl S 2009;40(10): 1615-20. http://dx.doi.org/10.1016/j.compositesa.2009.07.010.

[25] Scida D, Assarar M, Poilâne C, Ayad R. Influence of hygrothermal ageing on the damage mechanisms of flax-fibre reinforced epoxy composite. Compos Part BEng 2013;48:51-8. http://dx.doi.org/10.1016/j.compositesb.2012.12.010.

[26] Liu Q Stuart T, Hughes M, Sharma HSS, Lyons G. Structural biocomposites from flax Part II: The use of PEG and PVA as interfacial compatibilising agents. Compos Part A-Appl S 2007;38(5):1403-13. http://dx.doi.org/10.1016/j. compositesa.2006.08.009.

[27] Spārninš E, Nyström B, Andersons J. Interfacial shear strength of flax fibers in thermoset resins evaluated via tensile tests of UD composites. Int J Adhes Adhes 2012;36:39-43. http://dx.doi.org/10.1016/j. ijadhadh.2012.03.006.

[28] Lu T, Jiang M, Jiang Z, Hui D, Wang Z, Zhou Z. Effect of surface modification of bamboo cellulose fibers on mechanical properties of cellulose/epoxy composites. Compos Part B Eng 2013;51:28-34. http://dx.doi.org/10.1016/ j.compositesb.2013.02.031.

29] Lu T, Liu S, Jiang M, Xu X, Wang Y, Wang Z, et al. Effects of modifications of bamboo cellulose fibers on the improved mechanical properties of cellulose reinforced poly(lactic acid) composites. Compos Part B Eng 2014;62:191-7. http://dx.doi.org/10.1016/j.compositesb.2014.02.030.

[30] Baley C. Analysis of the flax fibres tensile behaviour and analysis of the tensile stiffness increase. Compos Part A-Appl S 2002;33(7):939-48. http:// dx.doi.org/10.1016/S1359-835X(02)00040-4

[31] Charlet K, Eve S, Jernot J, Gomina M, Breard J. Tensile deformation of a flax fiber. Procedia Eng 2009 Eng 2009;1(1):233-6. http://dx.doi.org/10.1016 j.proeng.2009.06.055.

[32] Coroller G, Lefeuvre A, Le Duigou A, Bourmaud A, Ausias G, Gaudry T, et al. Effect of flax fibres individualisation on tensile failure of flax/epoxy unidirectional composite. Compos Part A-Appl, S 2013;51:62-70. http://dx.doi.org/ 10.1016/j.compositesa.2013.03.018.

[33] Liang S, Gning P-B, Guillaumat L. Properties evolution of flax/epoxy composites under fatigue loading. Int J Fatigue 2014;63:36-45. http://dx.doi.org 10.1016/j.ijfatigue.2014.01.003.

[34] Shah DU. Developing plant fibre composites for structural applications by optimising composite parameters: A critical review. J Mater Sci 2013;48(18): 6083-107. http://dx.doi.org/10.1007/s10853-013-7458-7.

[35] Herakovich CT. Damage mechanics. Chapter 9.5. In: Mechanics of fibrous composites. New York, NY: John Wiley \& Sons, Inc; 1998. p. 332-61.

[36] Chaboche J-L. Damage mechanics. In: Comprehensive structural integrity, vol 2. Amsterdam; San Diego CA: Elsevier Pergamon; 2003. p. 213-84. Numerica and Computational Methods, vol. 2.

[37] Lemaitre J. How to use damage mechanics. Nucl Eng Des 1984;80(2):233-45. http://dx.doi.org/10.1016/0029-5493(84)90169-9.

[38] Lemaitre J, Chaboche J-L. Damage mechanics. Chapter 7. In: Mechanics of solid materials. Cambridge University Press; 1990. p. 346-450.

[39] Bos HL, Donald AM. In situ ESEM study of the deformation of elementary flax fibres. J Mater Sci 1999;34(13):3029-34. http://dx.doi.org/10.1023/A 1004650126890.

[40] Romhány G, Karger-Kocsis J, Czigány T. Tensile fracture and failure behavior of technical flax fibers. J Appl Polym Sci 2003;90(13):3638-45. http://dx.doi.org/ 10.1002/app.13110.

[41] Hughes M, Carpenter J, Hill C. Deformation and fracture behaviour of flax fibre reinforced thermosetting polymer matrix composites. J Mater Sci 2007;42(7): 2499-511. http://dx.doi.org/10.1007/s10853-006-1027-2.

[42] Shah DU. Damage in biocomposites: Stiffness evolution of aligned plant fibre composites during monotonic and cyclic fatigue loading. Compos Part A-App S 2016;83:160-8. http://dx.doi.org/10.1016/j. compositesa.2015.09.008.

[43] Thuault A, Domengès B, Hervas I, Gomina M. Investigation of the interna structure of flax fibre cell walls by transmission electron microscopy. Cellulose 2015;22(6):3521-30. http://dx.doi.org/10.1007/s10570-015-0744-6.

[44] Lamy B, Pomel C. Influence of fiber defects on the stiffness properties of flax fibers-epoxy composite materials. J Mater Sci Lett 2002;21(15):1211-3. http://dx.doi.org/10.1023/A:1016524619867.

[45] Hughes M. Defects in natural fibres: Their origin, characteristics and implications for natural fibre-reinforced composites. J Mater Sci 2011;47(2): 599-609. http://dx.doi.org/10.1007/s10853-011-6025-3.

[46] Aslan M, Chinga-Carrasco G, Sørensen BF, Madsen B. Strength variability of single flax fibres. J Mater Sci 2011;46(19):6344-54. http://dx.doi.org/10.1007/ s10853-011-5581-X.

[47] Lamy B, Baley C. Stiffness prediction of flax fibers-epoxy composite materials. J Mater Sci Lett 2000;19(11):979-80. http://dx.doi.org/10.1023/A 1006776423764.

48] Thomason JL, Carruthers J, Kelly J, Johnson G. Fibre cross-section determination and variability in sisal and flax and its effects on fibre performance characterisation. Compos Sci Technol 2011;71(7):1008-15. http://dx.doi.org/ 10.1016/j.compscitech.2011.03.007.

[49] Oksman K. High quality flax fibre composites manufactured by the resin transfer moulding process. J Reinf Plast Comp 2001;20(7):621-7. http:// dx.doi.org/10.1177/073168401772678634.

50] Romhány G, Karger-Kocsis J, Czigány T. Tensile fracture and failure behavior of thermoplastic starch with unidirectional and cross-ply flax fiber reinforcements. Macromol Mater Eng 2003;288(9):699-707. http://dx.doi.org/ 10.1002/mame.200300040.

51] Baley C, Perrot Y, Busnel F, Guezenoc H, Davies P. Transverse tensile behaviour of unidirectional plies reinforced with flax fibres. Mater Lett 2006;60(24): 2984-7. http://dx.doi.org/10.1016/j.matlet.2006.02.028.

52] De Rosa IM, Santulli C, Sarasini F. Acoustic emission for monitoring the mechanical behavior of natural fibre composites: A literature review. Compos Part A-Appl S 2009;40(9):1456-69. http://dx.doi.org/10.1016/ j.compositesa.2009.04.030.

[53] Shah DU, Schubel PJ, Clifford MJ, Licence P. The tensile behavior of off-axis loaded plant fiber composites: An insight on the nonlinear stress/strain response. Polym Compos 2012;33(9):1494-504. http://dx.doi.org/10.1002 PC 22279.

[54] Rask M, Madsen B, Sørensen BF, Fife JL, Martyniuk K, Lauridsen EM. In situ observations of microscale damage evolution in unidirectional natural fibre composites. Compos Part A-Appl S 2012;3(10):1639-49. http://dx.doi.org/ 10.1016/j.compositesa.2012.02.007.

[55] El Sawi I, Fawaz Z, Zitoune R, Bougherara H. An investigation of the damage mechanisms and fatigue life diagrams of flax fiber-reinforced polyme 
laminates. J Mater Sci 2014;49(5):2338-46. http://dx.doi.org/10.1007/ s10853-013-7934-0.

[56] Liang S, Gning P-B, Guillaumat L. Quasi-static behaviour and damage assessment of flax/epoxy composites. Mater Des 2015;67:344-53. http://dx.doi.org/ 10.1016/j.matdes.2014.11.048.

[57] Kersani M, Lomov S, Van Vuure A, Bouabdallah A, Verpoest I. Damage in flax/ epoxy quasiunidirectional woven laminates under quasi-static tension. J Compos Mater 2015;49(4):403-13. http://dx.doi.org/10.1177/ 0021998313519282.

[58] Panamoottil SM, Das R, Jayaraman K. Anisotropic continuum damage model for prediction of failure in flax/polypropylene fabric composites. Polym Compos 2016;37(8):2588-97. http://dx.doi.org/10.1002/pc.23453.

[59] Mahboob Z, El Sawi I, Zdero R, Fawaz Z, Bougherara H. Tensile and compressive damaged response in Flax fibre reinforced epoxy composites. Compos Part A-Appl S 2017;92:118-33. http://dx.doi.org/10.1016/ j.compositesa.2016.11.007.

[60] Facca AG, Kortschot MT, Yan N. Predicting the elastic modulus of natural fibre reinforced thermoplastics. Compos Part A-Appl S 2006;37(10):1660-71. http://dx.doi.org/10.1016/j.compositesa.2005.10.006.

[61] Facca AG, Kortschot MT, Yan N. Predicting the tensile strength of natural fibre reinforced thermoplastics. Compos Sci Technol 2007;67(1112):2454-66. http://dx.doi.org/10.1016/j.compscitech.2006.12.018.

[62] Andersons J, Modniks J, Spārninš E. Modeling the nonlinear deformation of flax-fiber-reinforced polymer matrix laminates in active loading. J Reinf Plast Comp 2015;34(3):248-56. http://dx.doi.org/10.1177/0731684414568043.

[63] Panamoottil SM, Das R, Jayaraman K. Towards a multiscale model for flax composites from behaviour of fibre and fibre/polymer interface. J Compos Mater 2016;51(6):859-73. http://dx.doi.org/10.1177/0021998316654303. 0021998316654303, Issn: 0021-9983, 1530-793X.

[64] Lemaitre J, Chaboche J-L. Mechanics of solid materials. Cambridge University Press; 1990.

[65] Voyiadjis GZ, Venson AR. Experimental damage investigation of a SiC-Ti aluminide metal matrix composite. Int J Damage Mech 1995;4(4):338-61. http:/ dx.doi.org/10.1177/105678959500400403.

[66] Poilâne C, Cherif ZE, Richard F, Vivet A, Ben Doudou B, Chen J. Polymer reinforced by flax fibres as a viscoelastoplastic material. Compos Struct 2014;112:100-12. http://dx.doi.org/10.1016/j.compstruct.2014.01.043.

[67] Sliseris J, Yan L, Kasal B. Numerical modelling of flax short fibre reinforced and flax fibre fabric reinforced polymer composites. Compos Part B-Eng 2016;89: 143-54. http://dx.doi.org/10.1016/j.compositesb. 2015.11.038.

[68] Ladevèze P, Le Dantec E. Damage modelling of the elementary ply for laminated composites. Compos Sci Technol 1992;43(3):257-67. http://dx.doi.org/ 10.1016/0266-3538(92)90097-M.

[69] Ladevèze P. A damage computational method for composite structures. Comput Struct 1992;44(12):79-87. http://dx.doi.org/10.1016/0045-7949(92) 90226-P.

[70] Le Dantec E. Contribution à la modélisation du comportement des composites stratifies. PhD thesis. Paris 6, France: Université Pierre et Marie Curie; July 1989. http://www.theses.fr/1989PA066299.

[71] Allix O, Ladevèze P. Interlaminar interface modelling for the prediction of delamination. Compos Struct 1992;22(4):235-42. http://dx.doi.org/10.1016/ 0263-8223(92)90060-P.

[72] Daudeville L, Ladevèze P. A damage mechanics tool for laminate delamination. Compos Struct 1993;25(1):547-55. http://dx.doi.org/10.1016/0263-8223(93) 90203-3.

[73] Allix O, Ladevèze P, Vittecoq E. Modelling and identification of the mechanical behaviour of composite laminates in compression. Compos Sci Technol 1994;51(1):35-42. http://dx.doi.org/10.1016/0266-3538(94)90154-6.

[74] Allix O, Ladevèze P, Corigliano A. Damage analysis of interlaminar fracture specimens. Compos Struct 1995;31(1):61-74. http://dx.doi.org/10.1016/ 0263-8223(95)00002-X

[75] Gasser A, Ladevèze P, Poss M. Damage mechanisms of a woven $\mathrm{SiC} / \mathrm{SiC}$ composite: Modelling and identification. Compos Sci Technol 1996;56(7): 779-84. http://dx.doi.org/10.1016/0266-3538(96)00020-6.

[76] Casari P, Ladevèze P, Chou T-W. In: Damage modeling and characterization of a three-dimensional woven composite. Paris: ICCM-12; 1999.. In: http:// www.iccm-central.org/Proceedings/ICCM12proceedings/site/htmlpap/ pap717.Htm.
[77] Johnson AF. Modelling fabric reinforced composites under impact loads. Compos Part A-Appl S 2001;32(9):1197-206. http://dx.doi.org/10.1016/ S1359-835X(00)00186-X.

[78] Allix O. A composite damage meso-model for impact problems. Compos Sci Technol 2001;61(15):2193-205. http://dx.doi.org/10.1016/S0266-3538(01) 00113-0.

[79] Guinard S, Allix O, Guédra-Degeorges D, Vinet A. A 3D damage analysis of lowvelocity impacts on laminated composites. Compos Sci Technol 2002;62(4): 585-9. http://dx.doi.org/10.1016/S0266-3538(01)00153-1.

[80] Knipprath C, Skordos AA, Pickett AK. In: A simplified discrete finite element model for non-crimp fabric composites. Stockholm: ECCM-13; 2008. https:// dspace.lib.cranfield.ac.uk/handle/1826/3067.

[81] Abisset E, Daghia F, Ladevèze P. On the validation of a damage mesomodel for laminated composites by means of open-hole tensile tests on quasi-isotropic laminates. Compos Part A-Appl S 2011;42(10):1515-24. http://dx.doi.org/ 10.1016/j.compositesa.2011.07.004.

[82] Feld N, Allix O, Baranger E, Guimard J-M. A micromechanics-based mesomodel for unidirectional laminates in compression up to failure. J Compos Mater 2012;46(23):2893-909. http://dx.doi.org/10.1177/ 0021998311434170

[83] Daghia F, Ladevèze P. Identification and validation of an enhanced mesomodel for laminated composites within the WWFE-III. J Compos Mater 2013;47(20-21):2675-93. http://dx.doi.org/10.1177/0021998313494095.

[84] Schueler D, Toso-Pentecôte N, Voggenreiter H. Simulation of high velocity impact on composite structures - Model implementation and validation. Appl Compos Mater 2016;23(4):857-78. http://dx.doi.org/10.1007/s10443-0169489-0.

[85] Ho M-P, Wang H, Lee J-H, Ho C-K, Lau K-T, Leng J, et al. Critical factors on manufacturing processes of natural fibre composites. Compos Part B Eng 2012;43(8):3549-62. http://dx.doi.org/10.1016/j.compositesb.2011.10.001.

[86] LINEO NV. Advanced Flax - FlaxPly. 2014. http://lineo.eu/products.

[87] ASTM D30 Committee. ASTM D3039 test method for tensile properties of polymer matrix composite materials. Tech. Rep. ASTM D3039. ASTM International; 2014.

[88] Chatzigeorgiou G, Charalambakis N, Chemisky Y, Meraghni F. Periodic homogenization for fully coupled thermomechanical modeling of dissipative generalized standard materials. Int J Plast 2016;81:18-39. http://dx.doi.org/ 10.1016/j.ijplas.2016.01.013.

[89] Corigliano A. Damage and fracture mechanics techniques for composite structures. In: Comprehensive structural integrity, vol. 3. Amsterdam; San Diego CA: Elsevier Pergamon; 2003. p. 459-539. Numerical and Computational Methods, vol. 3.

[90] Berthelot J-M. Composite materials: mechanical behaviour and structural analysis. Berlin Heidelberg: Springer- Verlag; 1999. http://link.springer.com/ 10.1007/978-1-4612-0527-2.

[91] Bensoussan A, Lions J-L, Papanicolaou G. Asymptotic analysis for periodic structures, vol. 374. Providence, Rhode Island: American Mathematical Society Chelsea Publishing; 2011.

[92] Sanchez-Palencia E. Non-homogeneous media and vibration theory, vol. 127 of Lecture notes in physics,. Berlin, Heidelberg: Springer Berlin Heidelberg; 1980. http://link.springer.com/10.1007/3-540-10000-8.

[93] Chatzigeorgiou G, Chemisky Y, Meraghni F. Computational micro to macro transitions for shape memory alloy composites using periodic homogenization. Smart Mater Struct 2015;24(3):035009. http://dx.doi.org/10.1088/09641726/24/3/035009.

[94] SMART+ Smart Materials Algorithms and Research Tools, http://www.lem3. $\mathrm{fr} /$ chemisky/smartplus/.

[95] Simo JC, Hughes TJR. Computational inelasticity, vol. 7 of Interdisciplinary applied mathematics. New York: Springer-Verlag; 1998. http://link.springer. com/10.1007/b98904.

[96] Chemisky Y, Meraghni F, Bourgeois N, Cornell S, Echchorfi R, Patoor E. Analysis of the deformation paths and thermomechanical parameter identification of a shape memory alloy using digital image correlation over heterogeneous tests. Int J Mech Sci 2015;96-97:13-24. http://dx.doi.org/10.1016/ j.ijmecsci.2015.03.007.

[97] Knipprath C. PhD dissertation. Mechanical performance of binder yarn composites. Cranfield, UK: Cranfield University; May 2010. http://dspace.lib. cranfield.ac.uk/handle/1826/6774. 